\title{
Tau-Based Treatment Strategies in Neurodegenerative Diseases
}

\author{
Anja Schneider*广 and Eckhard Mandelkow ${ }^{\ddagger}$ \\ *Department of Psychiatry and Psychotherapy, Von-Siebold-Strasse 5, University of Goettingen, 37075 Goettingen, Germany; \\ ${ }^{\dagger}$ Max-Planck-Institute for Experimental Medicine, Hermann-Rein-Strasse 3, 37075 Goettingen, Germany; and ${ }^{\ddagger}$ Max-Planck-Unit \\ for Structural Molecular Biology, clo DESY, Notkestrasse 85, 22607 Hamburg, Germany
}

\begin{abstract}
Summary: Neurofibrillary tangles are a characteristic hallmark of Alzheimer's and other neurodegenerative diseases, such as Pick's disease (PiD), progressive supranuclear palsy (PSP), corticobasal degeneration (CBD), and frontotemporal dementia and parkinsonism linked to chromosome 17 (FTDP-17). These diseases are summarized as tauopathies, because neurofibrillary tangles are composed of intracellular aggregates of the microtubule-associated protein tau. The molecular mechanisms of tau-mediated neurotoxicity are not well understood; however, pathologic hyperphosphorylation and aggregation of tau play a central role in neurodegeneration and neuronal dysfunction. The present review, therefore, focuses on therapeutic approaches that aim to inhibit tau phosphorylation and aggrega-
\end{abstract}

tion or to dissolve preexisting tau aggregates. Further experimental therapy strategies include the enhancement of tau clearance by activation of proteolytic, proteasomal, or autophagosomal degradation pathways or anti-tau directed immunotherapy. Hyperphosphorylated tau does not bind microtubules, leading to microtubule instability and transport impairment. Pharmacological stabilization of microtubule networks might counteract this effect. In several tauopathies there is a shift toward four-repeat tau isoforms, and interference with the splicing machinery to decrease four-repeat splicing might be another therapeutic option. Key Words: Tau, Alzheimer's disease, phosphorylation, aggregation, neurodegeneration, therapy.

\section{INTRODUCTION}

\section{Cell biology and function of tau}

The microtubule-associated protein (MAP) tau is expressed mainly in neurons, where it regulates microtubule assembly and stability. ${ }^{1,2}$ The synthesis of tau is upregulated along with tubulin during neuronal differentiation; in mature neurons, tau occurs mostly in the axon and is largely excluded from the somatodendritic compartment, whereas other MAPs (e.g., MAP2) predominate in dendrites. ${ }^{3,4}$ Microtubules must be able to dynamically grow and shrink, to support cellular shape changes. This is a prerequisite to establishing neuronal polarity and axonal outgrowth. ${ }^{5,6}$ In addition, microtubules serve as tracks for the transport of cellular cargoes (vesicles, organelles) along axons and dendrites. ${ }^{7}$ Both the dynamics and transport properties of microtubules are regulated by MAPs, such as tau. Their interactions are in turn regulated by post-translational modifications, such as phosphorylation. 8,9

Address correspondence and reprint requests to: Eckhard Mandelkow, Ph.D., Max-Planck-Unit for Structural Molecular Biology, c/o DESY, Notkestrasse 85, 22607 Hamburg, Germany. E-mail: mand@mpasmb.desy.de.
Due to its content of hydrophilic residues, tau is a highly soluble protein. ${ }^{10}$ It represents a prototype of the class of natively unfolded (or intrinsically unstructured) proteins. ${ }^{11}$ Six isoforms of tau are expressed in the adult human CNS by alternative splicing of exons 2,3 , and 10 of the single $M A P T$ gene (alias TAU) on chromosome 17q21.3; MAPT comprises 16 exons (FIG. 1B). ${ }^{12,13}$ Tau isoforms differ by the absence or presence of one or two N-terminal inserts $(\mathrm{N} 1, \mathrm{~N} 2)$, as well as exclusion or inclusion of the second of four pseudo-repeats $(\sim 31$ residues each) in the microtubule-binding domain (3R, 4R) (FIG. 1A). ${ }^{10,13}$ Tau-microtubule binding is mediated by the repeat domain and requires the presence of both $\mathrm{N}$ - and C-terminally flanking proline-rich domains which target tau to the microtubule surface. ${ }^{14}$ The number of repeats can modulate tau-microtubule affinity. ${ }^{15-17}$ Consistent with the weaker microtubule binding of three-repeat (3R) tau isoforms, only $3 R$ tau is expressed during neurogenesis, when higher microtubule dynamics are required. ${ }^{18}$ Phosphorylation of the repeat region and, to a lesser extent, also of the flanking regions impairs the tau-microtubule interaction and leads to tau detachment from microtubules. ${ }^{19,20}$

Whereas the microtubule interaction domain of tau resides in the C-terminal half (the assembly fragment), 

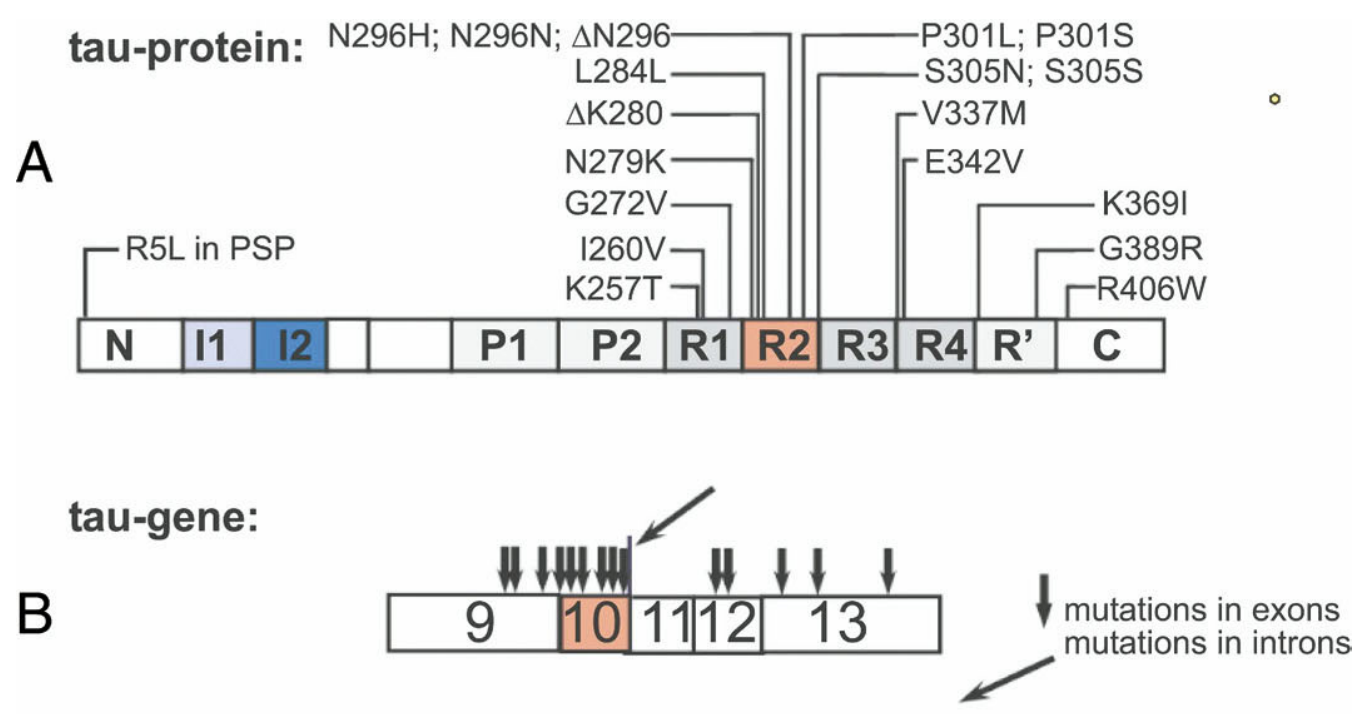

C

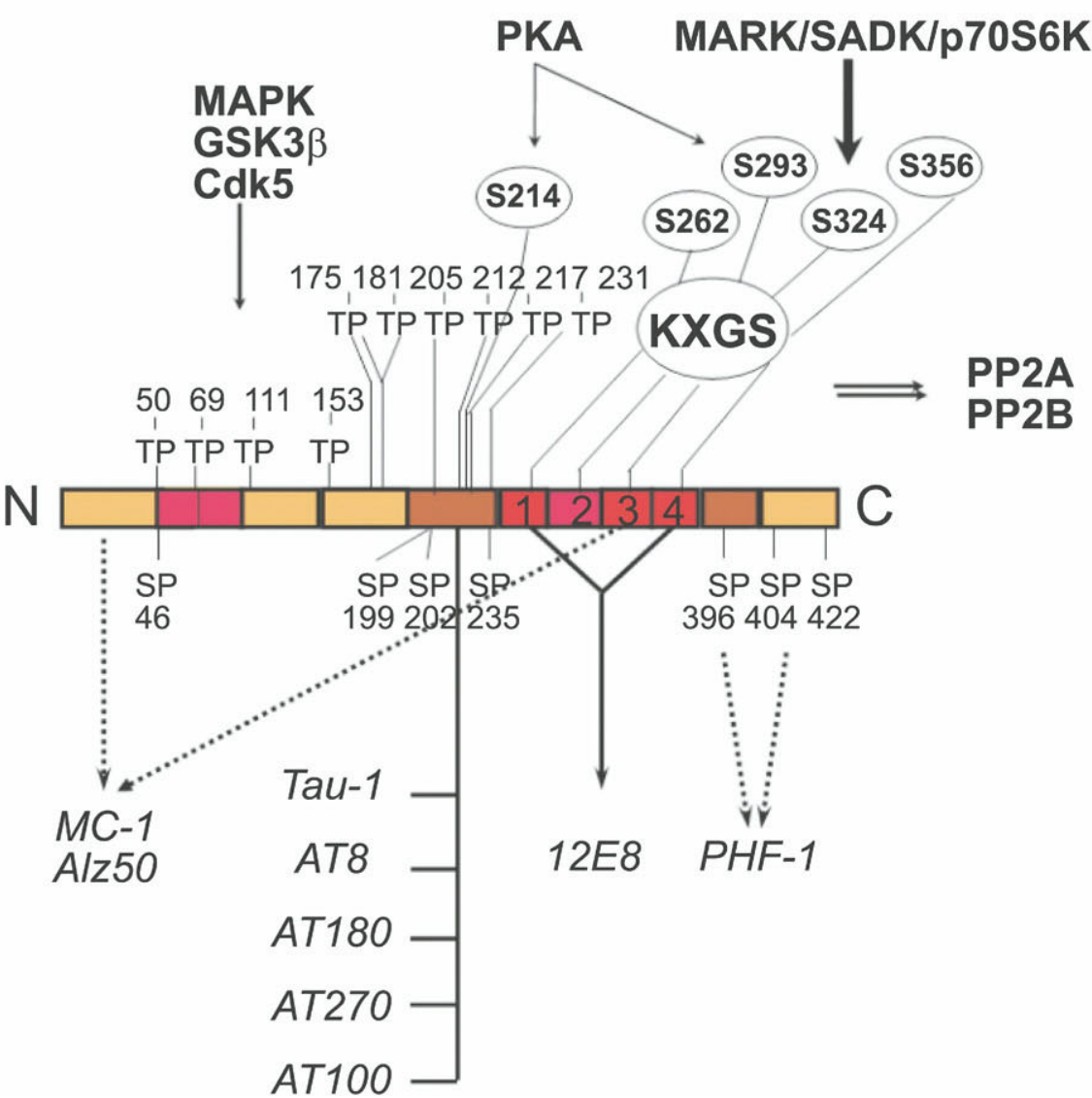

FIG. 1. Diagram of tau domains, mutations, phosphorylation sites, and antibody epitopes. (A) Human tau contains between 352 and 441 residues, depending on the splicing isoform. The isoforms are generated by the presence or absence of inserts I1, I2, and R2. The N-terminal half constitutes the projection domain, which protrudes away from the microtubule surface. The C-terminal half constitutes the assembly domain, which binds and stabilizes microtubules. The core of this domain is formed by the three or four repeats of $\sim 31$ residues each (R1-R4; R2 may be absent in the three-repeat isoforms of tau). The repeat domain is also responsible for the aggregation of tau into PHFs. The diagram shows many of the mutations observed in cases of FTDP-17. Most of them map to the repeat domain and may influence microtubule binding or PHF aggregation. $\triangle \mathrm{K} 280$ and P301L are two FTDP-17 mutations which are prone to aggregation. (B) Diagram of the tau gene in the region covering the repeat domain (exons 9-13). The MAPT gene consists of 16 exons. Exons 1 and 14 are not translated. The repeat domain is encoded by exons 9-12. Exclusion or inclusion of exon 10 gives rise to three-repeat or four-repeat tau isoforms. Most intronic tau mutations localize to the $5^{\prime}$ region of intron 10, they increase the incorporation of exon 10 (increased expression of 4R-isoforms), but they are silent on the protein level. Exon 10 mutations can also shift splicing toward four-repeat tau (for details, see http://www.alzforum.org). ${ }^{227}$ (C) Diagram of the longest tau isoform, tau441, with phosphorylation sites, kinases, and antibody epitopes. Tau isoforms differ by the presence or absence of $2 \mathrm{~N}$-terminal inserts N1, N2) and a second repetitive amino acid sequence, R2. Phosphorylation of S214 by PKA and S262/S356 by MARK, PKA, or other kinases leads to tau detachment from the microtubule. Phosphorylation of SP/TP sites in the flanking regions have a modulating effect on tau-microtubule affinity. Epitopes of different diagnostic phospho-epitopes are indicated. 
the N-terminal half projects away from the microtubule surface. ${ }^{21}$ Its functions are not well defined. It could act as a spacer, or interact with other proteinsfor example, signaling molecules such as kinases, phosphatases, heat shock proteins (HSPs) and other cytoskeletal elements. ${ }^{22-25}$ Because MAPs and microtubule motors both bind to the surface of microtubules, they can potentially interfere with each other. Thus, the overexpression of tau can retard motor-dependent transport, particularly in the anterograde direction. ${ }^{26-29}$ This can lead to oxidative damage and synaptic degeneration. ${ }^{30,31}$

\section{Tauopathies}

Filamentous or amorphous aggregates of hyperphosphorylated tau have been described in the context of various neurodegenerative diseases. These tauopathies cover a wide spectrum of neurodegenerative diseases with prominent tau pathology, including dementia syndromes (Alzheimer's disease [AD] and Pick's disease), which can be accompanied by parkinsonism (progressive supranuclear palsy [PSP], corticobasal degeneration [CBD], frontotemporal dementia and parkinsonism linked to chromosome 17 [FTDP-17]), and motor neuron diseases (amyotrophic lateral sclerosis-Parkinson-dementia complex, or ALS-PDC).

The neurofibrillary tangles (NFTs) of Alzheimer's disease consist of intracellular filamentous aggregates of hyperphosphorylated tau protein (FIG. 2). ${ }^{32,33}$ Tau can assemble into filamentous strands, which are termed either straight filaments or paired helical filaments (PHFs), depending on whether ultrastructure exhibits periodic crossovers of the two strands (FIG. 3). Twisted or nontwisted filaments of tau are found in AD, PSP, FTD, and CBD. Additionally, amorphous tau aggregates have been described in astrocytes of CBD brains. Hirano bodies,

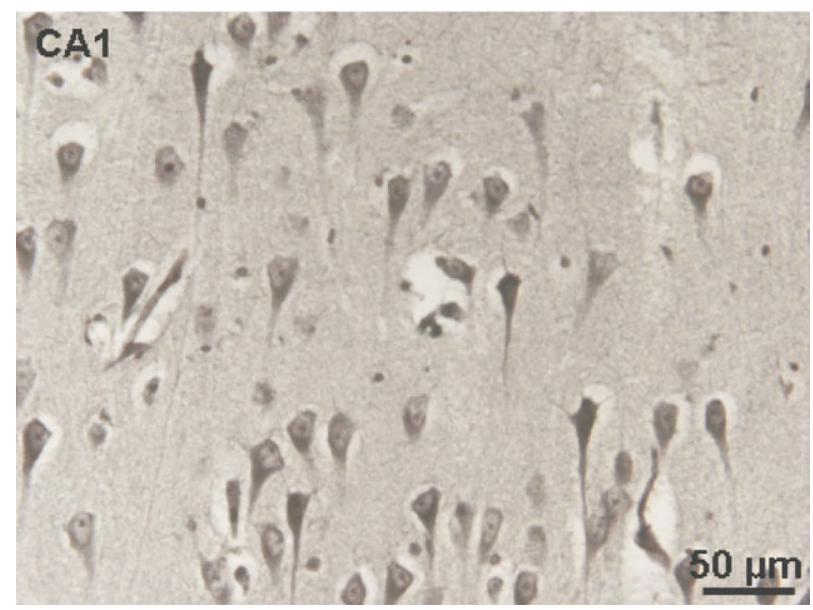

FIG. 2. Section from Alzheimer's disease (AD) brain, showing pyramidal cells of the hippocampal CA1 region with typical flame-shaped neurofibrillary tangles consisting of tau protein. Gallyas silver staining. (Courtesy of A. Nissen.)

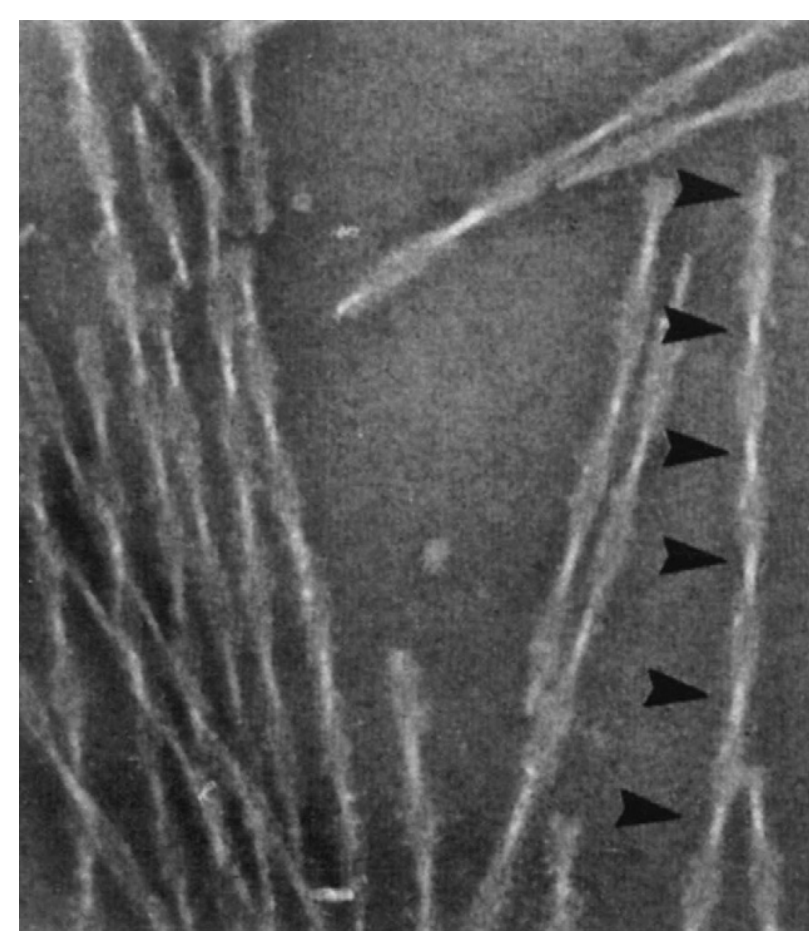

FIG. 3. Electron micrograph of negatively stained paired helical filaments isolated from AD brain. Note the two twisted strands with the typical crossover periodicity of $\sim 80 \mathrm{~nm}$ (arrowheads). (Courtesy of E.M. Mandelkow.)

which are actin-rich, paracrystalline structures that contain nonfibrillary aggregates of tau, have been identified in $\mathrm{AD}$ brain and in other tauopathies. ${ }^{34}$

Tau aggregates are not restricted to neurons but are also seen in glial cells, such as the coiled bodies and argyrophilic threads in oligodendrocytes of CBD and PSP, as well as the tufted astrocytes found in PSP. Tau pathology is predominant in oligodendrocytes in multisystem atrophy, and the various mutations of FTDP-17 differ by the proportion of neuronal or glial tau pathology. ${ }^{35,36}$ In AD patients, the number of NFTs correlates strongly with the degree of cognitive decline and neurodegeneration, and tau is commonly used as a diagnostic marker of $\mathrm{AD} .{ }^{37}$ The identification of patients in early disease stages is important, in light of recent findings of a positive correlation between early treatment with disease-modifying drugs and a prolonged maintenance of cognitive function. ${ }^{38}$

Total tau levels in CSF are elevated under circumstances of extensive neuronal degeneration, such as $\mathrm{AD}$, Creutzfeldt-Jakob syndrome, frontotemporal dementia (FTD), and stroke, but not in Parkinson's disease and progressive supranuclear palsy (PSP). ${ }^{39-43}$ The CSF levels of total and phosphorylated tau are therefore useful biomarkers for the diagnosis of $\mathrm{AD}$, in which phospho-tau concentrations in CSF are increased with an average sensitivity of $78 \%$ and specificity of $92 \% .{ }^{44,45}$ Especially high CSF concentrations of tau 
phosphorylated at T181, T231, S199, and S396/404 (FIG. 1B) have been suggested to be reliable predictors for the conversion of mild cognitive impairment into AD. ${ }^{46-48}$ Noninvasive diagnostic methods for tauopathies include positron emission tomography imaging with plaque-binding and especially tangle-binding tracers such as FDDNP, similar to the amyloidbinding radiotracer Pittsburgh compound B. ${ }^{49,50}$

\section{PATHOPHYSIOLOGY}

In $\mathrm{AD}$, tau pathology is accompanied by extracellular amyloid plaques and intracellular NFTs that are distributed mostly in the entorhinal region, hippocampus, and cortex. This is in contrast to other tauopathies, in which amyloid plaques are absent and NFTs are preferentially localized in different brain regions, such as the brain stem and basal ganglia (in PSP) or in the frontotemporal cortex (in FTDP-17). The identification of tau mutations in FTDP-17 families and in sporadic FTD has provided compelling evidence for a causative role for tau in neurodegeneration, rather than tau pathology being a mere side effect observed in neurodegenerative diseases. ${ }^{51-53}$

Tau mutations in FTDP-17 are either intronic, localized close to the splice-donor site following exon 10 and resulting in overproduction of four-repeat tau isoforms, or comprise missense, deletion, or silent mutations in the coding regions (FIG. 1B) ${ }^{52,53}$ The mutations lie mostly in or near the repeat domain, which constitutes the core of the microtubule binding domain and also the PHF assembly domain; the mutations result in reduced microtubule binding ability or in enhanced tau aggregation into PHFs (R5L, K257T, G272V, $\Delta$ K280, P301L, P301S, $\mathrm{V} 337 \mathrm{M}$, and R406W). ${ }^{54-60}$ Mutations in exon 10 can affect both protein properties and exon 10 splicing (e.g., $\Delta \mathrm{K} 280, \Delta \mathrm{N} 296$ and $\mathrm{N} 296 \mathrm{H}$ ), the latter shifting the isoform ratio of three- to four-repeat tau from approximately $1: 1$ in healthy individuals toward the four-repeat isoforms. ${ }^{61,62}$ Similar findings have been obtained in PSP and CBD, two tauopathies that share the MAPT H1 haplotype as a risk factor. ${ }^{63,64}$ Filamentous tau aggregates in PSP and CBD consist of four-repeat isoforms. ${ }^{65}$

Why tau, a highly soluble protein, aggregates into PHFs is still a matter of debate. In AD brains, tau is redistributed from the axonal to the somatodendritic compartment and is hyperphosphorylated at 25 different sites at least, which are known to interfere with the affinity of tau-microtubule binding (FIG. 1C). ${ }^{66}$ Pathologic hyperphosphorylation might thus lead to tau-microtubule detachment, subsequent instability of microtubule networks, impaired axonal transport and synaptic degeneration (FIG. 4). In addition to this loss-of-function effect, caused by microtubule instability, a toxic gain-offunction was assigned to aggregated PHF-tau (FIG. 4). ${ }^{67-69}$ Moreover, hyperphosphorylated, nonaggregated

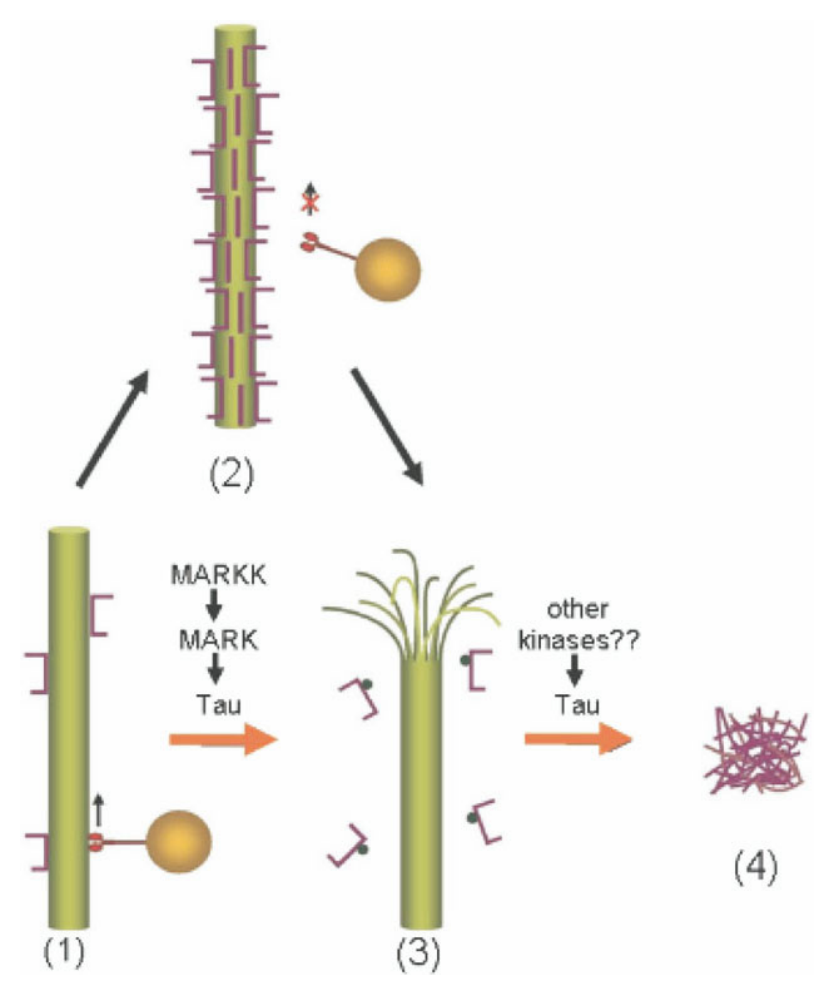

FIG. 4. Possible mechanisms of tau toxicity. (1) Microtubules stabilized by tau protein support axonal transport by motor proteins. (2) Excess bound tau can reduce the attachment of motor proteins and thus impair axonal traffic. (3) In AD, tau becomes hyperphosphorylated by several protein kinases (e.g., MARK) and detaches from microtubules. The microtubules break down (resulting in perturbed axonal transport) and the detached tau self-assembles into paired helical filaments. (4) The PHFs bundle together and form neurofibrillary tangles that obstruct the cell interior. $^{27}$

tau might be toxic by itself, as suggested by recent findings in Drosophila fruit fly and mouse models. ${ }^{70-73}$

Prevention of mis-splicing, hyperphosphorylation, and aggregation of tau are therefore promising therapeutic targets to interfere with tau-based toxicity and neurodegeneration. New approaches currently under intense investigation include various kinase and aggregation inhibitors, microtubule-stabilizing agents, enhancers of tau clearance (e.g., HSP90 inhibitors, immunotherapy), and recently described techniques to shift the ratio of misspliced tau toward three-repeat isoforms.

\section{TAU-BASED THERAPEUTIC APPROACHES}

\section{Antiphosphorylation strategies}

The largest tau isoform contains 45 serine (S), 35 threonine $(\mathrm{T})$, and 5 tyrosine $(\mathrm{Y})$ residues (FIG. 1C). Among these, 17 sites are part of serine/proline (SP) or threonine/proline (TP) motifs and represent targets of proline-directed SP/TP protein kinases such as glycogen synthase kinase $3 \beta$ (GSK-3 $\beta$ ), cyclin-dependent kinases (cdk5, cdc2), mitogen-activated protein kinase (MAPK), stress-activated kinases (JNK, p38), and others. ${ }^{74,75}$ Ad- 
ditional sites are targeted by different kinases, including cAMP-dependent protein kinase (PKA), protein kinase C (PKC), calcium/calmodulin dependent protein kinase II (CaMKII), serum- and glucocorticoid-inducible kinase (SGK), protein kinase B (PKB), microtubule-affinity regulating kinase (MARK), and SAD kinase (SADK). ${ }^{76}$ The KIGS or KCGS motifs in the repeat domain (S262, S293, S324, S356) can be phosphorylated by MARK, PKA, PKB, SADK, CaMKII, and p70S6K ${ }^{77-80}$ PKA additionally phosphorylates other sites including S214, a phospho-epitope that is especially upregulated during mitosis. ${ }^{81}$ In AD brain, tau is hyperphosphorylated at nearly all phosphorylation sites, with approximately nine phosphates per molecule, in contrast to the two to three phosphorylated residues observed in healthy control brains. ${ }^{82}$

Various antibodies directed against these phosphoepitopes preferentially recognize $\mathrm{AD}$ brain-derived tau and are used as diagnostic tools. Phosphorylation of S214 or the KXGS sites within the repeat domain strongly inhibits tau-microtubule binding, thereby raising soluble tau concentrations and increasing microtubule instability. Tau-microtubule detachment seems to be an early event in the course of the disease, because pretangle tau is phosphorylated at S262/S356 (12E8 epitope) in AD brains and in mouse models of tauopathy. ${ }^{83,84}$ Similarly, S214 phosphorylation was found to precede PHF formation in a triple transgenic mouse model of mutant APP, presenilin, and the FTDP-17 tau mutation P301L. ${ }^{85}$ However, phosphorylation of the KXGS motifs, especially S262, has been shown to inhibit the aggregation of tau into PHFs in vitro. ${ }^{86}$ Rather than promoting tau aggregation, the detachment from microtubules might render free cytosolic tau more accessible to phosphorylation by different SP/TP directed kinases than microtubule-bound tau would be.

There is a widespread assumption that hyperphosphorylation at SP or TP motifs leads to aggregation (although this is a matter of debate). Independently of aggregation, phosphorylation may be toxic to neurons (e.g., by microtubule destabilization, repeat domain phosphorylation) or by other mechanisms (e.g., activation of the mTOR pathway, SP/TP phosphorylation). ${ }^{87}$ Most approaches to interfering with tau phosphorylation rely on inhibiting different kinases or activation of phosphatases. ${ }^{88}$

MARK. The KXGS motifs in the repeat region of tau are phosphorylated by MARK/Par-1. The decreased microtubule affinity of KXGS phosphorylated tau and subsequent microtubule instability ${ }^{77}$ might be the mechanism by which MARK exerts its function in cell differentiation, neurite outgrowth, and maintenance of axonal transport. ${ }^{89-91}$ The PHF tau is hyperphosphorylated at S262/S356, and fluorescence resonance energy transfer experiments revealed active MARK in close proximity to phosphorylated S262/S356 residues in AD brain PHFs. ${ }^{92}$

MARK/Par-1 mediated S262/S356 phosphorylation was shown to enhance the toxic phenotype caused by human tau expression in the Drosophila fruit fly retina, which was absent in a S262A/S356A expressing mutant. $^{72}$ In addition, S262A/S356A mutants were less phosphorylated at SP/TP sites that become hyperphosphorylated during disease progression. ${ }^{83}$ This finding hints toward a priming effect of S262/S356 phosphorylation for subsequent pathological tau hyperphosphorylation.

MARK/Par-1 belongs to the calcium/calmodulin-dependent protein kinases. Its activity depends on phosphorylation by activating kinases (MARK kinase/thousand and one amino acid kinase [MARKK/TAO-1] or LKB1). ${ }^{91}$ Inhibitory regulation of MARK can additionally be achieved by binding to PAK5 or to scaffolding proteins or by subcellular localization. ${ }^{91,93}$ The activating MARKK is a member of the Ste20 family of kinases and phosphorylates MARK at a threonine residue in the activation loop. Other functions of MARKK/TAO- 1 involve mitosis progression and MAPK/p38 signaling upon stress induced activation. ${ }^{94,95}$ By these mechanisms, apart from the toxic effects of S262/S356 phosphorylated tau, MARKK might contribute to neurodegeneration and cell death.

Binding of testis-specific protein kinase 1 (TESK1) inhibits MARKK activity by protein-protein interaction. ${ }^{96,97}$ TESK1 is similar to LIM kinase, in that it phosphorylates cofilin and plays a role in the organization of the actin cytoskeleton. ${ }^{97-99}$ Note that active LIM kinase (LIMK) is also a downstream effector of $\mathrm{A} \beta$ mediated toxicity. ${ }^{100}$ Pharmacological inhibitors of MARK/MARKK include staurosporine (unselectively) and hymenialdisine, which also inhibits GSK $3 \beta .{ }^{90,101}$ Given the important and early role of MARK phosphorylation in the pathogenesis of tauopathies, the application of MARK inhibitors would be a worthwhile approach.

PKA. cAMP-dependent protein kinase A (PKA) has been shown to phosphorylate tau at S262/S356 and S214 in vitro and in vivo. ${ }^{102,103}$ Phosphorylation by PKA results in reduced microtubule-binding affinity and promotes the subsequent phosphorylation of different diagnostic phospho-epitopes. PKA phosphorylation at S214 is required to prime tau for its sequential phosphorylation by GSK-3 $\beta$, thereby giving rise to the AD-specific AT100 phospho-epitope. ${ }^{102}$ Activation of PKA by forskolin resulted in spatial memory deficits in rats. ${ }^{103}$ Isoquinoline sulfonamide derivatives and staurosporines are known to inhibit PKA with low selectivity and also affect PKG, PKC, and the myosin light chain kinase (MLCK). PKA inhibitors with higher selectivity are KT5720 and PKI. PKI binds to the catalytic subunit of PKA and promotes its nuclear export, thereby preventing 
cAMP response element regulated gene expression. ${ }^{104}$ However, none of these inhibitors have been tested in AD model systems to date.

Cdk5. Cyclin dependent kinase 5 (Cdk5) accumulates in tangle-bearing neurons of $\mathrm{AD}$ brains, and kinase activity was found to be upregulated in $\mathrm{AD} .{ }^{105} \mathrm{Cdk} 5$ is regulated by the neuron-specific activator $\mathrm{p} 35$. The myristoylated and membrane-bound domain of p35 can be cleaved by calpain to p25. This leads to a cytosolic redistribution of $\mathrm{p} 25$-bound cdk5 and aberrant tau phosphorylation. ${ }^{106}$ Overexpression of p25 in a rodent model resulted in increased tau phosphorylation and neurodegeneration and SP/TP phosphorylation by cdk5 increased tau toxicity in a Drosophila fruit fly model. ${ }^{71,107,108} \mathrm{Re}-$ cent evidence suggests that cdk5/p25 might be a downstream effector of $\mathrm{A} \beta$ mediated toxicity, leaving cdk5 as a promising therapeutic target. ${ }^{109}$ One must be aware, however, that the inhibition of cdk5 was accompanied by activation of GSK- $3 \beta$ in neuronal cell culture and that p35 knock-out mice revealed increased GSK-3 $\beta$ activity and tau phosphorylation. ${ }^{110,111}$

Cdk5 inhibition can be achieved by active site-directed inhibitors, by 2,6,9-trisubstituted purines and aloisines, which are small-molecule inhibitors that interfere with the cdk5/p25 complex formation (Cdk5 inhibitory peptide [CIP]), and by calpain inhibitors, which prevent p25 generation. ${ }^{101,112,113}$ The use of active site inhibitors is hampered by their lack of selectivity toward cdk5. Indirubins, which belong to the chemical class indolinones, also inhibit GSK-3. Likewise, purines are not highly selective for cdk5 and can inhibit ERK2. The purine roscovitine has been tested in p25 transgenic mice, and reduced tau phosphorylation and neurodegeneration was demonstrated upon roscovitine treatment. Roscovitine shows a higher selectivity toward cdk5 than olomoucine, another purine inhibitor of cyclin-dependent kinases, which has been tested successfully in Niemann Pick type C (NPC) mice, and aminopurvalanol, which efficiently inhibited cdk in vitro. ${ }^{114}$ Less cdk5 specificity is achieved by flavopiridol, indirubin, 1-aza-9-oxafluorenes, and aminothiazoles, all of which inhibit cyclindependent kinases in general in addition to GSK3. ${ }^{115}$ The cdk5 inhibitory peptide (CIP) interferes with cdk5/p25 binding and is more selective toward cdk5 than to other cyclin kinases. Calpain inhibitors have shown beneficial results in $\mathrm{AD}$ models, however their clinical application is restricted by their poor ability to cross the blood-brain barrier (BBB). ${ }^{116,117}$ In contrast, roscovitine has been described to penetrate the BBB at a sufficient rate. ${ }^{118}$

GSK3. The GSK- 3 isoforms $\alpha$ and $\beta$ are encoded by two different genes. ${ }^{119}$ Both isoforms are involved in glucose metabolism, cell proliferation, wnt signaling, and apoptosis. ${ }^{120,121}$ GSK-3 $\beta$ activity is regulated by phosphorylation; S9 phosphorylation inhibits kinase activity, and Y216 phosphorylation activates GSK-3 $\beta{ }^{121}$
Tau has been identified as an important substrate of GSK-3 in vitro and in vivo and can be phosphorylated at primed (e.g., T231) and unprimed epitopes (PHF-1, Tau-1, and AT8). ${ }^{122-124}$ Priming involves the prior phosphorylation of a serine or threonine residue, four amino acids C-terminal to the target phosphorylation site. ${ }^{125}$

Active GSK-3 was detected in pretangle neurons and NFTs in AD brains, and coexpression of the GSK-3 homolog shaggy with tau led to tau hyperphosphorylation, filamentous tau aggregation, and neurotoxicity in Drosophila fruit fly. ${ }^{126,127}$ In line with these findings, GSK-3 $\beta$ overexpressing transgenic mice showed increased tau phosphorylation and deficits in spatial memory. ${ }^{128,129}$ Tau phosphorylation by GSK-3 can be enhanced by $\mathrm{A} \beta$-treatment, which thus provides a possible link between tau and $A \beta$ pathology. ${ }^{130}$ GSK- $3 \beta$ activity is negatively regulated by phosphorylation at $S 9$ through different kinases (e.g., AKT-protein kinase B).

Various small-molecule inhibitors such as flavopiridol, paullones, and aloisines are directed against the ATP-binding site of GSK-3 and therefore display a low selectivity toward GSK $-3 \alpha$ or $-\beta$, and most of them also target cdk5. The recently described staurosporine-derived bisazaindolylmaleimide derivatives as well as pyrazolopyrazines and pyrazolopyridines are characterized by a higher selectivity toward GSK-3 $\beta$. Oral administration of the aminothiazole AR-A014418 resulted in decreased tau aggregation in a transgenic mouse model of P301L tau. ${ }^{131,132}$

Lithium, a well-characterized mood-stabilizer, competes with magnesium for GSK-3 binding; it leads to reduced tau-phosphorylation, aggregation and axonal degeneration in transgenic mice. ${ }^{133,134}$ Valproate, another mood-stabilizing drug (and an antiepileptic), also inhibits GSK- $3 \beta$ and is currently being tested in clinical AD trials.

Phosphatases. Tau is dephosphorylated by protein phosphatase-2A (PP-2A) and to a minor extent by PP-1 and $\mathrm{PP}-2 \mathrm{~B}$ (calcineurin). ${ }^{23,135}$ In $\mathrm{AD}$ brain, the mRNA levels of PP-2A and PP-1 are reduced compared with controls. ${ }^{136,137}$ A decrease in phosphatase activity might result in impaired tau dephosphorylation, as well as enhanced tau phosphorylation, because various tau-directed kinases are activated by phosphorylation themselves. Indeed, inhibition of PP-2A by okadaic acid resulted in AD-like tau hyperphosphorylation in rat brain slice cultures. ${ }^{138}$ To date, no pharmacologic approaches to activate PP-2A have been reported. However, memantine, an $N$-methyl-D-aspartate (NMDA) receptor antagonist that is well established for the treatment of $\mathrm{AD}$, has been described as antagonizing the okadaic acid-mediated inhibition of PP-2A in hippocampal slice cultures. ${ }^{139}$ These findings further support the choice of phosphatases as potential pharmacological targets in AD. 


\section{Antiaggregation strategies}

Tau, a natively unfolded protein, is highly soluble and does not readily aggregate into filaments. In vitro, polyanionic cofactors such as glycosaminoglycans, acidic peptides, RNA, or fatty acid micelles can promote PHF assembly. ${ }^{140-143}$ Aggregation is further promoted by high tau concentrations. In vitro studies have shown that tau phosphorylation is not necessary to drive tau into PHFs. ${ }^{140,141}$ On the contrary, phosphorylation of the KXGS motifs in the repeat region inhibits tau aggregation in vitro. ${ }^{86}$ Tau comprises two hydrophobic hexapeptide motifs ${ }^{144,145}$ in the repeat domains (275VQIINK280 at the beginning of R2 and 306VQIVYK311 at the beginning of R3) that form a cross $\beta$-structure and make up the PHF core. The $\mathrm{N}$ - and $\mathrm{C}$-terminal flanking regions are thought to form the PHF fuzzy coat. ${ }^{146}$ Proteolytic cleavage of the inhibitory $\mathrm{N}$ - and $\mathrm{C}$-termini exposes the aggregation-prone hexapeptide motifs, thereby greatly facilitating the nucleation of filaments. ${ }^{14,147}$

There has been debate on what form of tau is the toxic species for neurons. Elevation of tau, phosphorylation of tau at different sites, and truncation by different proteases have been investigated. ${ }^{148-150}$ Recent findings point to toxic functions of tau aggregates. For example, in stable tau cell lines, toxicity paralleled tau aggregation and removal of aggregates rescued the toxic phenotype. ${ }^{151,152}$ Similarly, in inducible transgenic mice, only the proaggregation tau was toxic; antiaggregation tau was not. ${ }^{68,69}$ Thus, preventing the buildup of aggregates by small-molecule inhibitors could be a promising strategy in the treatment of tauopathies. The non-neuroleptic phenothiazine methylene blue, which penetrates the BBB, and its desmethyl derivatives have been described to inhibit tau aggregation, with $K_{\mathrm{i}}$ values in the nanomolar range. ${ }^{153}$ Recent high-throughput screens yielded various potential drug candidates. Members of different substance classes, such as anthraquinones, $\mathrm{N}$-phenylamines, phenylthiazolhydrazides, and rhodanines, can inhibit tau aggregation and, even more importantly, disassemble existing filaments. ${ }^{67,154-156}$ The respective lead substances were identified in a high-throughput in vitro screen of approximately 200,000 compounds followed by chemical modification and retesting in a tau-expressing stable neuronal cell line with marked tau aggregation (FIG. 5). ${ }^{157}$

PTH. The phenylthiazolyl-hydrazides (PTH) (FIG. 5) were found by in silico screening of 77 primary screen hits. From this, 49 PTH derivatives were synthesized and a PTH lead structure as well as a structure-activity relationship could be verified. The structure-activity relationship distinguishes PTHs from nonselective inhibitors without a structure-activity relationship. ${ }^{155}$ The tauPTH interaction was studied by saturation transfer difference NMR and appeared to be hydrophobic. ${ }^{158}$ The exact structural interaction of tau and PTH still needs to be determined. One could envision interference with nu-

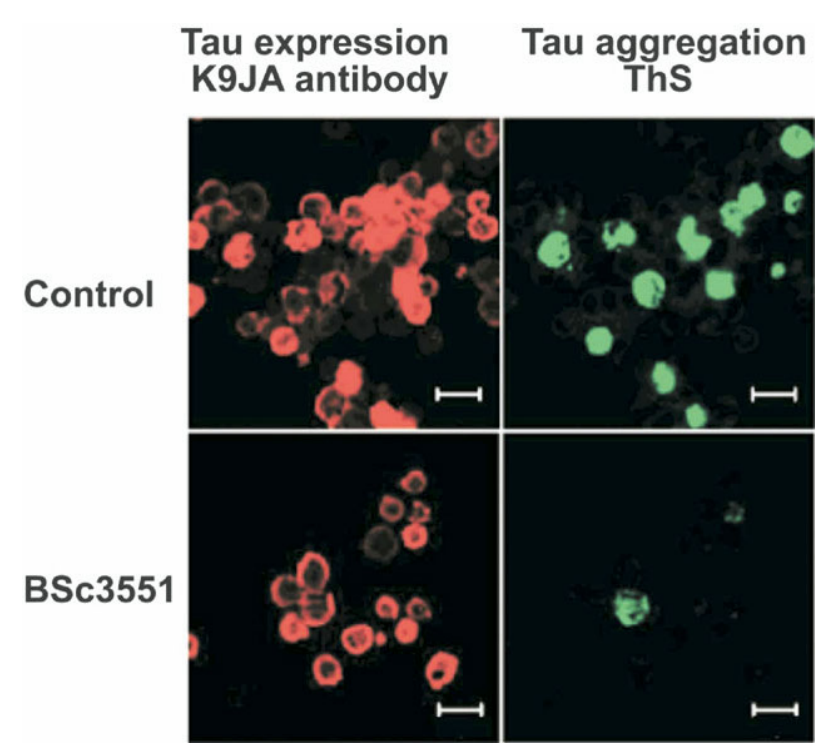

FIG. 5. Tau mutant expression, aggregation, and inhibition in a cellular model. The left panels show the expression of the tau repeat domain with the $\Delta \mathrm{K} 280$ mutation after addition of doxycycline in an inducible N2a cell line, stained with tau antibody (red). Tau aggregates are formed and can be detected by the fluorescence of thioflavine S (right, green). Top row, control without aggregation inhibitor compound, bottom row, with inhibitor BSc3551 (a phenylthiazolyl hydrazide derivative). Note the strong reduction of aggregation by the compound. Scale bar: 20 $\mu \mathrm{m}$. (Modified from Pickhardt et al. ${ }^{155}$ )

cleation or elongation steps of tau assembly, either mediated by steric inhibition of tau-tau interaction, stabilization of a non-aggregation prone tau conformation or interaction with polyanionic cofactors of aggregation.

Rhodanines and anthraquinones. The recently published substance class of rhodanines is preferable to anthraquinones, due to reduced cytotoxicity and absence of mutagenicity. Notably, a rhodanine derivative, the aldose reductase inhibitor epalrestat, showed no toxic side effects in a long-term clinical trial. ${ }^{159,160}$ Different rhodanine derivatives inhibit tau aggregation and promote filament disassembly in a cell culture model, with efficacies in the nanomolar range and in the absence of obvious cytotoxicity or interference with microtubule stability. ${ }^{156}$

$\mathrm{N}$-phenylamines. $\mathrm{N}$-phenylamines were proved to have a comparable activity as rhodanines, but show a lower pharmacological potency in vitro ${ }^{67}$ It will now be interesting to test these substances in mouse models for bioavailability and pharmacokinetics.

Thiacarbocyanines. Another class of small-molecule inhibitors of tau aggregation are thiacarbocyanine dyes, such as N744, which were identified by in vitro screens. ${ }^{161,162}$ A multivalent cyane derivative, the cyclic bis-thiacarbocyanine, inhibits tau aggregation in vitro with approximately a fourfold higher potency than the monovalent cyane itself. ${ }^{163}$ The mechanism by which multivalent ligands interfere with protein aggregation 
has been speculated to involve their binding to oligomers, thereby preventing incorporation of new molecules into filaments. ${ }^{164}$ Alternatively, these small-molecule inhibitors might decrease the concentration of aggregation-prone proteins by sequestration into protein-inhibitor complexes. ${ }^{165}$ Developing multivalent cyanes, which are characterized by an improved potency due to an increased local concentration of ligands, might therefore be a promising strategy.

\section{Tau clearance}

Another possible approach to prevent tau toxicity could be the augmentation of its cellular clearance, as well as the degradation of tau aggregates.

Proteasome and autophagosome activation. Ubiquitin-proteasome and autophagy-lysosomal pathways are the two major means of protein degradation within the cell. ${ }^{166}$ Oligomers or higher-order aggregates cannot enter the proteasome for steric reasons, but will be degraded by autophagy. During autophagy, a double membrane is formed around the intracellular aggregate. This autophagosome then fuses with the lysosome (autolysosome), where acidic lysosomal hydrolases degrade the contents of the vesicle. ${ }^{167}$ Autophagy has been described for intracellular protein aggregates such as polyQ-huntingtin and $\alpha$-synuclein aggregates, and also for tau. ${ }^{168,169}$ Rapamycin inhibits mTOR (mammalian target of rapamycin), thereby promoting autophagy. In a Drosophila fruit fly model expressing wild-type or R406W mutant tau, treatment with rapamycin induced autophagic tau degradation and diminished tau-induced toxicity. ${ }^{169}$ It has been speculated that the nonclassic, proteasome-independent K63 ubiquitin pathway is involved in the autophagic route of tau. This notion is supported by the finding that P301L tau-positive inclusions in a neuronal cell line were cleared after stimulation of autophagy, a mechanism that was impaired by coexpression of the ubiquitin mutant K63R. ${ }^{170}$

Note, however, that the beneficial effect on tau clearance by stimulating autophagy might be counteracted by increased $\mathrm{A} \beta$ production in the autophagosomal system, as has been proposed by Rubinsztein et al. ${ }^{171,172}$

The chaperones HSP27 and HSP90 are involved in phosphorylation-dependent proteasomal degradation of tau. ${ }^{24,173}$ HSP90-interacting proteins are degraded by the proteasome upon pharmacological inhibition of HSP90. Phosphorylation of the flanking regions enhanced the proteasomal degradation of tau in transfected cell lines that were treated with HSP90 inhibitors. ${ }^{173}$ Phosphorylation of S262/S356 protected tau against proteasomal degradation. The HSP90 inhibitor geldanamycin is not feasible for clinical studies because of hepatotoxic side effects, but its less toxic derivatives 17-AAG and 17DMAG have been tested as anticancer treatment in a clinical setting. ${ }^{174}$ Their pharmacological properties, however, suggest a poor ability to cross the BBB. Recently, several HSP90 inhibitors of low molecular weight have been described, which might reach sufficient therapeutic CNS concentrations. ${ }^{173}$

PHF-tau has been shown to be ubiquitinated at least at four different sites, and through different lysine linkages on ubiquitin. ${ }^{175,176}$ Tau is predominantly monoubiquitinated, and only a minor part of PHF-tau is linked to polyubiquitin chains by Lys42. Conjugation sites for monoubiquitination have been identified within the repeat region. They include Lys254, Lys257, Lys311, and Lys317, with Lys311 being a major linkage site. ${ }^{176}$ The HSP70 co-chaperone CHIP (the acronym stands for the carboxyl terminus of the Hsc70-interacting protein) functions as the primary E3-ligase in ubiquitin-dependent tau clearance. ${ }^{177-180}$ In line with the important function of CHIP in tau clearance, increased tau accumulation was reported in CHIP knock-out mice. ${ }^{178}$ Activation of the co-chaperone CHIP could prove to be an attractive drug target, especially because it also stabilizes full length APP against secretase cleavage. In addition, CHIP directs APP to proteasomal degradation, by promoting APP ubiquitination. It also accelerates $\mathrm{A} \beta_{42}$ removal and can protect against $\mathrm{A} \beta$ toxicity. ${ }^{181}$

Proteases. It has been assumed that cytosolic proteases might also play a role in tau degradation. Recently, the puromycin-sensitive aminopeptidase PSA, a 100-kDa M1 metalloprotease, was identified by a genomic approach screening for modifiers of tauopathy. ${ }^{182}$ Besides its function in protein turnover, PSA is involved in cell cycle regulation, and a wide range of PSA substrates are known, including enkephalins, cholecystokinin, and somatostatin, among many others. ${ }^{183,184}$ Tau has been identified as a substrate of PSA in vitro. PSA mediated amino-terminal tau degradation of $\mathrm{AD}$ brain-derived soluble or insoluble tau was impaired, relative to control tau. ${ }^{185}$ At first sight, activation of PSA appears to be an attractive therapeutic target, but regarding the large number of physiologic processes in which PSA is involved, side effects are likely to occur.

When activating tau proteolysis, it has to be considered that proteolytic tau fragments of the repeat domain might act as a seed for tau aggregation. A stepwise proteolysis of the tau repeat domain has been described in an inducible FTDP- $17 \Delta 280$ mutant tau cell line. ${ }^{151}$ There, a PHF nucleating fragment was generated by subsequent cleavage, first between K257/S258, followed by cleavage at $\mathrm{I} 360$ or K353. The responsible protease has not yet been identified, and it is not known whether it is upregulated in AD. This could, however, be a promising target for pharmacological inhibition.

Two cysteine proteases, caspase- 3 and calpain- 1 , have been described as downstream targets of $\mathrm{A} \beta$-induced toxicity in cell culture models. In cultured hippocampal neurons, $\mathrm{A} \beta$-induced toxicity was mediated by calpain- 1 
activation and generation of a $17-\mathrm{kD}$ tau fragment. Both tau fragmentation and neurotoxic effects of $\mathrm{A} \beta$ could be diminished by calpain-1 inhibition. ${ }^{186}$ To date, however, no direct proof for the suggested neurotoxicity of the $17-\mathrm{kD}$ tau fragment has been provided.

Tau can be cleaved in vitro by the serine-aspartyl protease caspase-3 at Asp 421 , which increased and accelerated the aggregation of both truncated and full-length tau. In addition, the caspase- 3 cleaved tau fragment exerted toxic effects in tissue-culture experiments. ${ }^{187-189}$ Caspase- 3 is activated in $\mathrm{AD}$, and PHFs from AD-brains were recognized by antibodies directed against the caspase- 3 cleavage site of tau. ${ }^{150,187,188}$ The caspase-3 specific inhibitor AcDEVD-CHO inhibited tau cleavage and reduced $A \beta$-mediated toxicity in organotypic rat brain slices. ${ }^{190}$

\section{Tau vaccination}

Intriguing new treatment strategies, currently being investigated in multicenter clinical trials, involve passive and active immunization against $\mathrm{A} \beta$. Approximately $0.1 \%$ of total circulating $\mathrm{IgG}$ is found within the CNS. ${ }^{191}$ $\mathrm{IgG}$ is assumed to enter the CNS via BBB-deficient regions and $\mathrm{BBB}$ transcytosis, and CNS entry might be enhanced by an increased BBB permeability, as has been described for AD. ${ }^{192-195}$ Similar vaccination approaches have been tested for a tau-directed immunotherapy in mice, even though tau aggregates are intracellular (in contrast to amyloid plaques). ${ }^{196,197}$ Neuronal pinocytic uptake of antibodies has been reported, partially mediated by the neuronal $\mathrm{Fc} \gamma$ or Thy 1.1 receptors. ${ }^{198-204}$ This increases the probability of targeting intracellular tau by an antibody-mediated approach. However, no explanation has been provided as to how tau antibodies, once in endosomal compartments, interact with the cytosolic tau protein, nor how tau immunocomplexes, once formed, are cleared by $\mathrm{Fc} \gamma$-receptors or astrocytes and microgliamediated phagocytosis.

Despite such concerns, one could imagine immunomediated clearance of extracellular PHFs, the so-called ghost tangles, and tau-based immunotherapy was further encouraged by the reduction of intracellular $\alpha$-synuclein aggregates in synuclein vaccinated transgenic mice. ${ }^{205} \mathrm{In}$ the case of tau, P301L transgenic mice were immunized with a phospho-tau peptide (containing the phosphorylated PHF-1 epitope). ${ }^{196}$ These mice responded with antibody synthesis, less of histochemically detectable tau aggregates, and slower progression of behavior deficits, compared with untreated mice. The feasibility of tauimmunotherapy must be considered critically, however, given that vaccination of C57BL/6 mice with recombinant human tau protein resulted in the onset of neurofibrillary tangle pathology, axon damage, demyelination, and gliosis. ${ }^{197}$ This is an important finding, especially in the light of the first clinical $\mathrm{A} \beta$ immunization trial, which was terminated after the detection of profound neuroinflammation in some immunized patients. ${ }^{206}$

\section{Isoform approaches}

In approximately half of the FTDP-17 mutations, a twofold to sixfold excess of four-repeat tau over threerepeat isoforms was observed, whereas both isoforms are expressed in equal proportions in normal adult brain. ${ }^{53,207}$ The hypothesis that four-repeat tau isoforms might play a pathogenic role is further strengthened by the predominance of filamentous tau aggregates, consisting of four-repeat isoforms, in FTDP-17 mutations and in PSP and CBD brain..$^{208-211}$ In addition, sporadic tauopathies are strongly correlated with the MAPT H1 haplotype, from which approximately 1.4-fold more four-repeat tau isoforms are generated than from the $\mathrm{H} 2$ haplotype. ${ }^{63,64,212}$ No difference in the ratio of four- and three-repeat isoforms was found in total postmortem $\mathrm{AD}$ brain tau, but a roughly 1.5 -fold excess of four-repeat tau has been reported in the temporal cortices of $\mathrm{AD}$ brains. $^{207,213,214}$

Four-repeat tau binds microtubules with a higher affinity than three-repeat tau, and an isoform imbalance in favor of four-repeat isoforms might impair kinesin-dependent anterograde traffic, because tau and kinesins bind to the microtubule surface in a competitive fashion. $^{28,30,146}$ Shifting the tau isoform ratio from fourrepeat to three-repeat isoforms by alternative splicing was therefore proposed as a therapeutic option in tauopathies. Promising results have already been achieved, with antisense oligonucleotides directed against the splice junction of exon 10 in PC12 cells leading to reduced exon 10 splicing. ${ }^{215}$

Spliceosome-mediated RNA trans-splicing (SMarT) is another method for mRNA reprogramming, and has been tested in tau transfected cells. ${ }^{26,217}$ Trans-splicing occurs between the $5^{\prime}$ splice site of a pre-mRNA and the $3^{\prime}$ splice site of a second mRNA at the spliceosome. With SMarT, the endogenous target pre-mRNA becomes trans-spliced to an exogenously delivered pre-transsplicing molecule. This contains a binding domain that interacts with the $3^{\prime}$ end of the target pre-mRNA intron. As a proof of principle, an exogenous pre-trans-splicing RNA comprising human tau exons 10 to 13 and a binding sequence complementary to the $3^{\prime}$ end of intron 9 were transfected into cells expressing tau exons 9, 10, and 11 . The resulting trans-spliced tau chimera contained exons 9 to 13 with a correct and exact exon 9 to exon 10 junction. Shifting the ratio from four- to three-repeat tau could be achieved in a similar way, with a pre-transsplicing construct containing exons 11 to 13 together with the intron 9 binding site.

Besides interfering with defective alternative splicing, the SMarT method has been successfully applied to express the correct transcripts in the case of dominant 
mutations such as cystic fibrosis and hemophilia A. ${ }^{218,219}$ The application of this exciting method in animal models of tauopathy has not been studied to date, and might be hindered by the difficulty of RNA entry into brain cells.

\section{Microtubule-stabilizing drugs}

The rationale behind microtubule-binding drug approaches in tauopathies is to compensate for the putative loss-of-function of abnormally hyperphosphorylated or aggregated tau that no longer binds and stabilizes microtubules. PHF tau cannot stabilize microtubules, and this leads to microtubule decay, transport impairment, and synaptic degeneration (FIG. 4). ${ }^{146}$ Indeed, a microtubule stability marker, acetylated $\alpha$-tubulin, is reduced in AD neurons. In tissue culture, phosphorylation of tau repeats resulted in transport impairment, and deficits in fast anterograde transport were described in tau transgenic mice. $^{27,220}$

One major advantage of microtubule-stabilizing strategies is the availability of approved and well-established chemotherapeutic drugs such as taxol. Taxol and its derivative taxane analog TX67 stabilize microtubules and promote tubulin polymerization. ${ }^{221}$ Weekly taxol treatment of tau transgenic mice over 12 weeks restored fast anterograde transport, increased the number of axonal microtubules, and diminished motor deficits. ${ }^{222}$ Other microtubule-stabilizing approaches are reviewed by Michelis et al. ${ }^{223,224}$

The neuronal tubulin-preferring agent NAP was reported to display less side effects than the non-cell-typespecific taxol, which inhibits cell mitosis in general. ${ }^{225}$ The octapeptide NAPVSIPQ (NAP) has a preference for neuronal tubulin and crosses the BBB readily when administered intranasally. Continuous NAP treatment of a triple transgenic mouse model characterized by $\mathrm{A} \beta$ and tau-based pathology reduced the levels of hyperphosphorylated soluble and insoluble tau and enhanced the cognitive function of these mice. ${ }^{85,225}$

\section{PERSPECTIVES}

Compelling evidence supports the crucial role of tau in the pathogenic cascade in AD and other tauopathies (Fig. 4). Therapeutic approaches to interfere with tau-mediated toxicity are still in the stage of scientific validation and clearly more work will be needed before any of these experimental strategies will find their way into clinical application. Interest in tau is growing, especially after discovery of several tau mutations in FTDP-17 and in light of recent reports that suggested tau as a downstream mediator of a $\beta$-conferred toxicity. ${ }^{186,226}$ Counteracting tau neurotoxicity will therefore be a promising strategy, and even more so when combined with anti-A $\beta$ directed approaches.
Acknowledgments: We are grateful to Dr. Eva-Maria Mandelkow for suggestions and critical reading of the manuscript.

\section{REFERENCES}

1. Weingarten MD, Lockwood AH, Hwo SY, Kirschner MW. A protein factor essential for microtubule assembly. Proc Natl Acad Sci U S A 1975;72:1858-1862.

2. Cleveland DW, Hwo SY, Kirschner MW. Purification of tau, a microtubule-associated protein that induces assembly of microtubules from purified tubulin. J Mol Biol 1977;116:207-225.

3. Drubin DG, Caput D, Kirschner MW. Studies on the expression of the microtubule-associated protein, tau, during mouse brain development, with newly isolated complementary DNA probes. J Cell Biol 1984;98:1090-1097.

4. Binder LI, Frankfurter A, Rebhun LI. The distribution of tau in the mammalian central nervous system. J Cell Biol 1985;101: 1371-1378.

5. Kirschner M, Mitchison T. Beyond self-assembly: from microtubules to morphogenesis. Cell 1986;45:329-342.

6. Caceres A, Kosik KS. Inhibition of neurite polarity by tau antisense oligonucleotides in primary cerebellar neurons. Nature 1990;343:461-463.

7. Sheetz MP, Vale R, Schnapp B, et al. Vesicle movements and microtubule-based motors. J Cell Sci Suppl 1986;5:181-188.

8. Sloboda RD, Rudolph SA, Rosenbaum JL, Greengard P. Cyclic AMP-dependent endogenous phosphorylation of a microtubuleassociated protein. Proc Natl Acad Sci U S A 1975;72:177-181.

9. Mandell JW, Banker GA. Microtubule-associated proteins, phosphorylation gradients, and the establishment of neuronal polarity. Perspect Dev Neurobiol 1996;4:125-135.

10. Lee G, Cowan N, Kirschner M. The primary structure and heterogeneity of tau protein from mouse brain. Science 1988;239: 285-288.

11. Schweers O, Schönbrunn-Hanebeck E, Marx A, Mandelkow E. Structural studies of tau protein and Alzheimer paired helical filaments show no evidence for $\beta$-structure. J Biol Chem 1994; 269:24290-24297.

12. Andreadis A, Brown WM, Kosik KS. Structure and novel exons of the human tau gene. Biochemistry 1992;31:10626-10633.

13. Goedert M, Spillantini MG, Jakes R, Rutherford D, Crowther RA. Multiple isoforms of human microtubule-associated protein tau: sequences and localization in neurofibrillary tangles of Alzheimer's disease. Neuron 1989;3:519-526.

14. Preuss U, Biernat J, Mandelkow EM, Mandelkow E. The 'jaws' model of tau-microtubule interaction examined in $\mathrm{CHO}$ cells. J Cell Sci 1997;110:789-800.

15. Butner KA, Kirschner MW. Tau protein binds to microtubules through a flexible array of distributed weak sites. J Cell Biol 1991;115:717-730.

16. Goode BL, Feinstein SC. Identification of a novel microtubule binding and assembly domain in the developmentally regulated inter-repeat region of tau. J Cell Biol 1994;124:769-782.

17. Panda D, Samuel JC, Massie M, Feinstein SC, Wilson L. Differential regulation of microtubule dynamics by three- and fourrepeat tau: implications for the onset of neurodegenerative disease. Proc Natl Acad Sci U S A 2003;100:9548-9553.

18. Nothias F, Boyne L, Murray M, Tessler A, Fischer I. The expression and distribution of tau proteins and messenger RNA in rat dorsal root ganglion neurons during development and regeneration. Neuroscience 1995;66:707-719.

19. Biernat J, Gustke N, Drewes G, Mandelkow EM, Mandelkow E. Phosphorylation of Ser262 strongly reduces binding of tau to microtubules: distinction between PHF-like immunoreactivity and microtubule binding. Neuron 1993;11:153-163.

20. Bramblett GT, Goedert M, Jakes R, Merrick SE, Trojanowski JQ, Lee VM. Abnormal tau phosphorylation at Ser396 in Alzheimer's disease recapitulates development and contributes to reduced microtubule binding. Neuron 1993;10:1089-1099.

21. Hirokawa N, Shiomura Y, Okabe S. Tau proteins: the molecular structure and mode of binding on microtubules. J Cell Biol 1988; 107:1449-1459. 
22. Chen J, Kanai Y, Cowan NJ, Hirokawa N. Projection domains of MAP2 and tau determine spacings between microtubules in dendrites and axons. Nature 1992;360:674-677.

23. Sontag E, Nunbhakdi-Craig V, Lee G, Bloom GS, Mumby MC. Regulation of the phosphorylation state and microtubule-binding activity of Tau by protein phosphatase 2A. Neuron 1996;17: 1201-1207.

24. Shimura H, Miura-Shimura Y, Kosik KS. Binding of tau to heat shock protein 27 leads to decreased concentration of hyperphosphorylated tau and enhanced cell survival. J Biol Chem 2004; 279:17957-17962.

25. Selden SC, Pollard TD. Phosphorylation of microtubule-associated proteins regulates their interaction with actin filaments. J Biol Chem 1983;258:7064-7071.

26. Ebneth A, Godemann R, Stamer K, Illenberger S, Trinczek B, Mandelkow E. Overexpression of tau protein inhibits kinesindependent trafficking of vesicles, mitochondria, and endoplasmic reticulum: implications for Alzheimer's disease. J Cell Biol 1998; 143:777-794.

27. Mandelkow EM, Stamer K, Vogel R, Thies E, Mandelkow E. Clogging of axons by tau, inhibition of axonal traffic and starvation of synapses. Neurobiol Aging 2003;24:1079-1085.

28. Seitz A, Kojima H, Oiwa K, Mandelkow EM, Song YH, Mandelkow E. Single-molecule investigation of the interference between kinesin, tau and MAP2c. EMBO J 2002;21:4896-4905.

29. Dixit R, Ross JL, Goldman YE, Holzbaur EL. Differential regulation of dynein and kinesin motor proteins by tau. Science 2008; 319:1086-1089.

30. Stamer K, Vogel R, Thies E, Mandelkow E, Mandelkow EM. Tau blocks traffic of organelles, neurofilaments, and APP vesicles in neurons and enhances oxidative stress. J Cell Biol 2002;156: 1051-1063.

31. Thies E, Mandelkow EM. Missorting of tau in neurons causes degeneration of synapses that can be rescued by the kinase MARK2/Par-1. J Neurosci 2007;27:2896-2907.

32. Brion JP, Flament-Durand J, Dustin P. Alzheimer's disease and tau proteins. Lancet 1986;2(8515): 1098.

33. Grundke-Iqbal I, Iqbal K, Quinlan M, Tung YC, Zaidi MS, Wisniewski HM. Microtubule-associated protein tau: a component of Alzheimer paired helical filaments. J Biol Chem 1986; 261:6084-6089.

34. Hirano A. Hirano bodies and related neuronal inclusions. Neuropathol Appl Neurobiol 1994;20:3-11.

35. Arima K. Ultrastructural characteristics of tau filaments in tauopathies: immuno-electron microscopic demonstration of tau filaments in tauopathies. Neuropathology 2006;26:475-483.

36. Berry RW, Quinn B, Johnson N, Cochran EJ, Ghoshal N, Binder LI. Pathological glial tau accumulations in neurodegenerative disease: review and case report. Neurochem Int 2001;39:469479.

37. Thal DR, Holzer M, Rüb U, et al. Alzheimer-related tau-pathology in the perforant path target zone and in the hippocampal stratum oriens and radiatum correlates with onset and degree of dementia. Exp Neurol 2000;163:98-110.

38. Lane RM, Potkin SG, Enz A. Targeting acetylcholinesterase and butyrylcholinesterase in dementia. Int J Neuropsychopharmacol 2006;9:101-124.

39. Kapaki E, Kilidireas K, Paraskevas GP, Michalopoulou M, Patsouris E. Highly increased CSF tau protein and decreased $\beta$-amyloid $_{1-42}$ in sporadic CJD: a discrimination from Alzheimer's disease? J Neurol Neurosurg Psychiatry 2001;71:401-403.

40. Blennow K, Wallin A, Agren H, Spenger C, Siegfried J, Vanmechelen E. Tau protein in cerebrospinal fluid: a biochemical marker for axonal degeneration in Alzheimer disease? Mol Chem Neuropathol 1995;26:231-245.

41. Sjögren M, Minthon L, Davidsson P, et al. CSF levels of tau, $\beta$-amyloid - $_{-42}$ and GAP-43 in frontotemporal dementia, other types of dementia and normal aging. J Neural Transm 2000;107: 563-579.

42. Formichi P, Battisti C, Radi E, et al. Cerebrospinal fluid tau, $\mathrm{A} \beta$, and phosphorylated tau protein for the diagnosis of Alzheimer's disease. J Cell Physiol 2006;208:39-46.
43. Ganzer S, Arlt S, Schoder V, et al. CSF-tau, CSF-A $\beta_{1-42}$, ApoEgenotype and clinical parameters in the diagnosis of Alzheimer's disease: combination of CSF-tau and MMSE yields highest sensitivity and specificity. J Neural Transm 2003;110:1149-1160.

44. Blennow K, Hampel H. CSF markers for incipient Alzheimer's disease. Lancet Neurol 2003;2:605-613.

45. Hampel H, Mitchell A, Blennow K, et al. Core biological marker candidates of Alzheimer's disease: perspectives for diagnosis, prediction of outcome and reflection of biological activity. J Neural Transm 2004;111:247-272.

46. Diniz BS, Pinto JA Jr, Forlenza OV. Do CSF total tau, phosphorylated tau, and $\beta$-amyloid 42 help to predict progression of mild cognitive impairment to Alzheimer's disease? A systematic review and meta-analysis of the literature. World J Biol Psychiatry 2008 Jan 29 (Epub ahead of print).

47. Ewers M, Buerger K, Teipel SJ, et al. Multicenter assessment of CSF-phosphorylated tau for the prediction of conversion of MCI Neurology 2007;69:2205-2212.

48. Buerger K, Ewers M, Andreasen N, et al. Phosphorylated tau predicts rate of cognitive decline in MCI subjects: a comparative CSF study. Neurology 2005;65:1502-1503.

49. Small GW, Kepe V, Ercoli LM, et al. PET of brain amyloid and tau in mild cognitive impairment. N Engl J Med 2006;355:2652 2663.

50. Klunk WE, Engler H, Nordberg A, et al. Imaging brain amyloid in Alzheimer's disease with Pittsburgh Compound-B. Ann Neurol 2004:55:306-319.

51. Poorkaj P, Bird TD, Wijsman E, et al. Tau is a candidate gene for chromosome 17 frontotemporal dementia [Erratum in: Ann Neurol 1998;44:428]. Ann Neurol 1998;43:815-825.

52. Hutton M, Lendon CL, Rizzu P, et al. Association of missense and $5^{\prime}$-splice-site mutations in tau with the inherited dementia FTDP-17. Nature 1998;393:702-705.

53. Spillantini MG, Murrell JR, Goedert M, Farlow MR, Klug A, Ghetti B. Mutation in the tau gene in familial multiple system tauopathy with presenile dementia. Proc Natl Acad Sci U S A 1998:95:7737-7741.

54. Hasegawa M, Smith MJ, Goedert M. Tau proteins with FTDP-17 mutations have a reduced ability to promote microtubule assembly. FEBS Lett 1998;437:207-210.

55. Hong M, Zhukareva V, Vogelsberg-Ragaglia V, et al. Mutationspecific functional impairments in distinct tau isoforms of hereditary FTDP-17. Science 1998;282:1914-1917.

56. Dayanandan R, Van Slegtenhorst M, Mack TG, et al. Mutations in tau reduce its microtubule binding properties in intact cells and affect its phosphorylation. FEBS Lett 1999;446:228-232.

57. Nacharaju P, Lewis J, Easson C, et al. Accelerated filament formation from tau protein with specific FTDP-17 missense mutations. FEBS Lett 1999;447:195-199.

58. Goedert M, Jakes R, Crowther RA. Effects of frontotemporal dementia FTDP-17 mutations on heparin-induced assembly of tau filaments. FEBS Lett 1999;450:306-311.

59. Gamblin TC, King ME, Dawson $\mathrm{H}$, et al. In vitro polymerization of tau protein monitored by laser light scattering: method and application to the study of FTDP-17 mutants. Biochemistry 2000; 39:6136-6144.

60. Barghorn S, Zheng-Fischhöfer Q, Ackmann M, et al. Structure, microtubule interactions, and paired helical filament aggregation by tau mutants of frontotemporal dementias. Biochemistry 2000; 39:11714-11721.

61. D'Souza I, Poorkaj P, Hong M, et al. Missense and silent tau gene mutations cause frontotemporal dementia with parkinsonismchromosome 17 type, by affecting multiple alternative RNA splicing regulatory elements. Proc Natl Acad Sci U S A 1999; 96:5598-5603.

62. Grover A, DeTure M, Yen SH, Hutton M. Effects on splicing and protein function of three mutations in codon N296 of tau in vitro. Neurosci Lett 2002;323:33-36.

63. Baker M, Litvan I, Houlden H, et al. Association of an extended haplotype in the tau gene with progressive supranuclear palsy. Hum Mol Genet 1999;8:711-715.

64. Houlden H, Baker M, Morris HR, et al. Corticobasal degeneration 
and progressive supranuclear palsy share a common tau haplotype. Neurology 2001;56:1702-1706.

65. Togo T, Sahara N, Yen SH, et al. Argyrophilic grain disease is a sporadic 4-repeat tauopathy. J Neuropathol Exp Neurol 2002;61: $547-556$.

66. Anderton BH, Betts J, Blackstock WP, et al. Sites of phosphorylation in tau and factors affecting their regulation. Biochem Soc Symp 2001;(67):73-80.

67. Khlistunova I, Biernat J, Wang Y, et al. Inducible expression of Tau repeat domain in cell models of tauopathy: aggregation is toxic to cells but can be reversed by inhibitor drugs. J Biol Chem 2006;281:1205-1214.

68. Eckermann K, Mocanu MM, Khlistunova I, et al. The $\beta$-propensity of Tau determines aggregation and synaptic loss in inducible mouse models of tauopathy. J Biol Chem 2007;282:3175531765 .

69. Mocanu MM, Nissen A, Eckermann K, et al. The potential for $\beta$-structure in the repeat domain of tau protein determines aggregation, synaptic decay, neuronal loss, and coassembly with endogenous Tau in inducible mouse models of tauopathy. J Neurosci 2008;28:737-748.

70. Steinhilb ML, Dias-Santagata D, Fulga TA, Felch DL, Feany MB. Tau phosphorylation sites work in concert to promote neurotoxicity in vivo. Mol Biol Cell 2007;18:5060-5068.

71. Steinhilb ML, Dias-Santagata D, Mulkearns EE, et al. S/P and T/P phosphorylation is critical for tau neurotoxicity in Drosophila. J Neurosci Res 2007;85:1271-1278.

72. Nishimura I, Yang Y, Lu B. PAR-1 kinase plays an initiator role in a temporally ordered phosphorylation process that confers tau toxicity in Drosophila. Cell 2004;116:671-682.

73. Santacruz K, Lewis J, Spires T, et al. Tau suppression in a neurodegenerative mouse model improves memory function. Science 2005;309:476-481.

74. Buée L, Bussière T, Buée-Scherrer V, Delacourte A, Hof PR. Tau protein isoforms, phosphorylation and role in neurodegenerative disorders. Brain Res Brain Res Rev 2000;33:95-130.

75. Gong CX, Liu F, Grundke-Iqbal I, Iqbal K. Post-translational modifications of tau protein in Alzheimer's disease. J Neural Transm 2005;112:813-838.

76. Yang YC, Lin CH, Lee EH. Serum- and glucocorticoid-inducible kinase 1 (SGK1) increases neurite formation through microtubule depolymerization by SGK1 and by SGK1 phosphorylation of tau. Mol Cell Biol 2006;26:8357-8370.

77. Drewes G, Ebneth A, Preuss U, Mandelkow EM, Mandelkow E. MARK, a novel family of protein kinases that phosphorylate microtubule-associated proteins and trigger microtubule disruption. Cell 1997;89:297-308.

78. Kishi M, Pan YA, Crump JG, Sanes JR. Mammalian SAD kinases are required for neuronal polarization. Science 2005;307:929932.

79. Pei JJ, Khatoon S, An WL, et al. Role of protein kinase B in Alzheimer's neurofibrillary pathology. Acta Neuropathol 2003; 105:381-392.

80. Pei JJ, Braak H, An WL, et al. Up-regulation of mitogen-activated protein kinases ERK1/2 and MEK1/2 is associated with the progression of neurofibrillary degeneration in Alzheimer's disease. Brain Res Mol Brain Res 2002;109:45-55.

81. Illenberger S, Zheng-Fischhöfer Q, Preuss U, et al. The endogenous and cell cycle-dependent phosphorylation of tau protein in living cells: implications for Alzheimer's disease. Mol Biol Cell 1998;9:1495-1512.

82. Morishima-Kawashima M, Hasegawa M, Takio K, et al. Hyperphosphorylation of tau in PHF. Neurobiol Aging 1995;16:365371; discussion 371-380.

83. Augustinack JC, Schneider A, Mandelkow EM, Hyman BT. Specific tau phosphorylation sites correlate with severity of neuronal cytopathology in Alzheimer's disease. Acta Neuropathol 2002; 103:26-35.

84. Drewes G, Trinczek B, Illenberger S, et al. Microtubule-associated protein/microtubule affinity-regulating kinase (p110mark): a novel protein kinase that regulates tau-microtubule interactions and dynamic instability by phosphorylation at the Alzheimerspecific site serine 262. J Biol Chem 1995;270:7679-7688.
85. Oddo S, Caccamo A, Shepherd JD, et al. Triple-transgenic model of Alzheimer's disease with plaques and tangles: intracellular $\mathrm{A} \beta$ and synaptic dysfunction. Neuron 2003;39:409-421.

86. Schneider A, Biernat J, von Bergen M, Mandelkow E, Mandelkow EM. Phosphorylation that detaches tau protein from microtubules (Ser262, Ser214) also protects it against aggregation into Alzheimer paired helical filaments. Biochemistry 1999;38: 3549-3558.

87. Khurana V, Lu Y, Steinhilb ML, Oldham S, Shulman JM, Feany MB. TOR-mediated cell-cycle activation causes neurodegeneration in a Drosophila tauopathy model. Curr Biol 2006;16:230241.

88. Kosik KS, Ahn J, Stein R, Yeh LA. Discovery of compounds that will prevent tau pathology. J Mol Neurosci 2002;19:261-266.

89. Mandelkow EM, Thies E, Trinczek B, Biernat J, lkow E. MARK/ PAR1 kinase is a regulator of microtubule-dependent transport in axons. J Cell Biol 2004;167:99-110.

90. Biernat J, Wu YZ, Timm T, et al. Protein kinase MARK/PAR-1 is required for neurite outgrowth and establishment of neuronal polarity. Mol Biol Cell 2002;13:4013-4028.

91. Timm T, Li XY, Biernat J, et al. MARKK, a Ste20-like kinase, activates the polarity-inducing kinase MARK/PAR-1. EMBO J 2003;22:5090-5101.

92. Chin JY, Knowles RB, Schneider A, Drewes G, Mandelkow EM, Hyman BT. Microtubule-affinity regulating kinase (MARK) is tightly associated with neurofibrillary tangles in Alzheimer brain: a fluorescence resonance energy transfer study. J Neuropathol Exp Neurol 2000;59:966-971.

93. Matenia D, Griesshaber $\mathrm{B}, \mathrm{Li} \mathrm{XY}$, et al. PAK5 kinase is an inhibitor of MARK/Par-1, which leads to stable microtubules and dynamic actin. Mol Biol Cell 2005;16:4410-4422.

94. Draviam VM, Stegmeier F, Nalepa G, et al. A functional genomic screen identifies a role for TAO1 kinase in spindle-checkpoint signalling. Nat Cell Biol 2007;9:556-564.

95. Raman M, Earnest S, Zhang K, Zhao Y, Cobb MH. TAO kinases mediate activation of $\mathrm{p} 38$ in response to DNA damage. EMBO J 2007;26:2005-2014.

96. Toshima J, Toshima JY, Takeuchi K, Mori R, Mizuno K. Cofilin phosphorylation and actin reorganization activities of testicular protein kinase 2 and its predominant expression in testicular Sertoli cells. J Biol Chem 2001;276:31449-31458.

97. Johne C, Matenia D, Li XY, Timm T, Balusamy K, Mandelkow EM. Spred1 and TESK1: two new interaction partners of the kinase MARKK/TAO1 that link the microtubule and actin cytoskeleton. Mol Biol Cell 2008;19:1391-1401.

98. LaLonde DP, Brown MC, Bouverat BP, Turner CE. Actopaxin interacts with TESK1 to regulate cell spreading on fibronectin J Biol Chem 2005;280:21680-21688.

99. Tsumura Y, Toshima J, Leeksma OC, Ohashi K, Mizuno K. Sprouty- 4 negatively regulates cell spreading by inhibiting the kinase activity of testicular protein kinase. Biochem J 2005;387: 627-637.

100. Heredia L, Helguera P, de Olmos S, et al. Phosphorylation of actin-depolymerizing factor/cofilin by LIM-kinase mediates amyloid $\beta$-induced degeneration: a potential mechanism of neuronal dystrophy in Alzheimer's disease. J Neurosci 2006;26:65336542.

101. Meijer L, Thunnissen AM, White AW, et al. Inhibition of cyclindependent kinases, GSK-3 $\beta$ and CK1 by hymenialdisine, a marine sponge constituent. Chem Biol 2000;7:51-63.

102. Zheng-Fischhöfer Q, Biernat J, Mandelkow EM, Illenberger S, Godemann R, Mandelkow E. Sequential phosphorylation of Tau by glycogen synthase kinase- $3 \beta$ and protein kinase $\mathrm{A}$ at Thr212 and Ser214 generates the Alzheimer-specific epitope of antibody AT100 and requires a paired-helical-filament-like conformation. Eur J Biochem 1998;252:542-552.

103. Liu SJ, Zhang JY, Li HL, et al. Tau becomes a more favorable substrate for GSK-3 when it is prephosphorylated by PKA in rat brain. J Biol Chem 2004;279:50078-50088.

104. Shuntoh H, Sakamoto N, Matsuyama S, et al. Molecular structure of the $\mathrm{C} \beta$ catalytic subunit of rat cAMP-dependent protein kinase and differential expression of $\mathrm{C} \alpha$ and $\mathrm{C} \beta$ isoforms in rat tissues and cultured cells. Biochim Biophys Acta 1992;1131:175-180. 
105. Pei JJ, Grundke-Iqbal I, Iqbal K, Bogdanovic N, Winblad B, Cowburn RF. Accumulation of cyclin-dependent kinase 5 (cdk5) in neurons with early stages of Alzheimer's disease neurofibrillary degeneration. Brain Res 1998;797:267-277.

106. Lee MS, Kwon YT, Li M, Peng J, Friedlander RM, Tsai LH. Neurotoxicity induces cleavage of p35 to p25 by in. Nature 2000;405:360-364.

107. Noble W, Olm V, Takata K, et al. Cdk5 is a key factor in tau aggregation and tangle formation in vivo. Neuron 2003;38:555565 .

108. Cruz JC, Tseng HC, Goldman JA, Shih H, Tsai LH. Aberrant Cdk5 activation by $\mathrm{p} 25$ triggers pathological events leading to neurodegeneration and neurofibrillary tangles. Neuron 2003;40: 471-483.

109. Lopes JP, Oliveira CR, Agostinho P. Role of cyclin-dependent kinase 5 in the neurodegenerative process triggered by amyloid- $\beta$ and prion peptides: implications for Alzheimer's disease and prion-related encephalopathies. Cell Mol Neurobiol 2007;27: 943-957.

110. Morfini G, Szebenyi G, Brown H, et al. A novel CDK5-dependent pathway for regulating GSK3 activity and kinesin-driven motility in neurons. EMBO J 2004;23:2235-2245.

111. Hallows JL, Chen K, DePinho RA, Vincent I. Decreased cyclindependent kinase 5 (cdk5) activity is accompanied by redistribution of cdk5 and cytoskeletal proteins and increased cytoskeletal protein phosphorylation in p35 null mice. J Neurosci 2003;23: 10633-10644.

112. Johnson K, Liu L, Majdzadeh N, et al. Inhibition of neuronal apoptosis by the cyclin-dependent kinase inhibitor GW8510: identification of $3^{\prime}$ substituted indolones as a scaffold for the development of neuroprotective drugs. J Neurochem 2005;93: $538-548$.

113. Camins A, Verdaguer E, Folch J, Canudas AM, Pallàs M. The role of CDK5/P25 formation/inhibition in neurodegeneration. Drug News Perspect 2006;19:453-460.

114. Rosania GR, Merlie J Jr, Gray N, Chang YT, Schultz PG, Heald R. A cyclin-dependent kinase inhibitor inducing cancer cell differentiation: biochemical identification using Xenopus egg extracts. Proc Natl Acad Sci U S A 1999;96:4797-4802.

115. Tsai LH. The inducible p25 transgenic mouse as an Alzheimer's disease model. Presented at: Alzheimer's disease: from molecular mechanisms to drug discovery, Cancun, Mexico, Dec 11-17, 2004.

116. Higuchi M, Iwata N, Saido TC. Understanding molecular mechanisms of proteolysis in Alzheimer's disease: progress toward therapeutic interventions. Biochim Biophys Acta 2005;1751:6067.

117. Saez ME, Ramirez-Lorca R, Moron FJ, Ruiz A. The therapeutic potential of the calpain family: new aspects. Drug Discov Today 2006;11:917-923.

118. Vita M, Abdel-Rehim M, Olofsson S, et al. Tissue distribution, pharmacokinetics and identification of roscovitine metabolites in rat. Eur J Pharm Sci 2005;25:91-103.

119. Woodgett JR. cDNA cloning and properties of glycogen synthase kinase-3. Methods Enzymol 1991;200:564-577.

120. Grimes CA, Jope RS. The multifaceted roles of glycogen synthase kinase $3 \beta$ in cellular signaling. Prog Neurobiol 2001;65: 391-426.

121. Doble BW, Woodgett JR. GSK-3: tricks of the trade for a multitasking kinase. J Cell Sci 2003;116:1175-1186.

122. Lovestone S, Reynolds CH, Latimer D, et al. Alzheimer's disease-like phosphorylation of the microtubule-associated protein tau by glycogen synthase kinase-3 in transfected mammalian cells. Curr Biol 1994;4:1077-1086.

123. Hong M, Lee VM. Insulin and insulin-like growth factor-1 regulate tau phosphorylation in cultured human neurons. J Biol Chem 1997;272:19547-19553.

124. Muñoz-Montaño JR, Moreno FJ, Avila J, Diaz-Nido J. Lithium inhibits Alzheimer's disease-like tau protein phosphorylation in neurons. FEBS Lett 1997;411:183-188.

125. Li T, Paudel HK. Glycogen synthase kinase $3 \beta$ phosphorylates Alzheimer's disease-specific Ser396 of microtubule-associated protein tau by a sequential mechanism. Biochemistry $2006 ; 45$ : $3125-3133$.

126. Pei JJ, Tanaka T, Tung YC, Braak E, Iqbal K, Grundke-Iqbal I. Distribution, levels, and activity of glycogen synthase kinase- 3 in the Alzheimer disease brain. J Neuropathol Exp Neurol 1997;56: 70-78.

127. Jackson GR, Wiedau-Pazos M, Sang TK, et al. Human wild-type tau interacts with wingless pathway components and produces neurofibrillary pathology in Drosophila. Neuron 2002;34:509_ 519.

128. Hernández F, Borrell J, Guaza C, Avila J, Lucas JJ. Spatial learning deficit in transgenic mice that conditionally over-express GSK-3 $\beta$ in the brain but do not form tau filaments. J Neurochem 2002;83:1529-1533.

129. Lucas JJ, Hernández F, Gómez-Ramos P, Morán MA, Hen R, Avila J. Decreased nuclear $\beta$-catenin, tau hyperphosphorylation and neurodegeneration in GSK-3 $\beta$ conditional transgenic mice. EMBO J 2001;20:27-39.

130. Alvarez G, Muñoz-Montaño JR, Satrústegui J, Avila J, Bogónez E, Díaz-Nido J. Regulation of tau phosphorylation and protection against $\beta$-amyloid-induced neurodegeneration by lithium: possible implications for Alzheimer's disease. Bipolar Disord 2002;4: 153-165.

131. Churcher I. Tau therapeutic strategies for the treatment of Alzheimer's disease. Curr Top Med Chem 2006;6:579-595.

132. Bhat R, Xue Y, Berg S, et al. Structural insights and biological effects of glycogen synthase kinase 3-specific inhibitor ARA014418. J Biol Chem 2003;278:45937-45945.

133. Phiel CJ, Klein PS. Molecular targets of lithium action. Annu Rev Pharmacol Toxicol 2001;41:789-813.

134. Noble W, Planel E, Zehr C, et al. Inhibition of glycogen synthase kinase- 3 by lithium correlates with reduced tauopathy and degeneration in vivo. Proc Natl Acad Sci U S A 2005;102:6990-6995.

135. Sun L, Liu SY, Zhou XW, et al. Inhibition of protein phosphatase 2A- and protein phosphatase 1-induced tau hyperphosphorylation and impairment of spatial memory retention in rats. Neuroscience 2003;118:1175-1182.

136. Vogelsberg-Ragaglia V, Schuck T, Trojanowski JQ, Lee VM. PP2A mRNA expression is quantitatively decreased in Alzheimer's disease hippocampus. Exp Neurol 2001;168:402-412.

137. Gong CX, Shaikh S, Wang JZ, Zaidi T, Grundke-Iqbal I, Iqbal K. Phosphatase activity toward abnormally phosphorylated tau: decrease in Alzheimer disease brain. J Neurochem 1995;65:732738.

138. Pei JJ, Gong CX, An WL, et al. Okadaic-acid-induced inhibition of protein phosphatase $2 \mathrm{~A}$ produces activation of mitogen-activated protein kinases ERK1/2, MEK1/2, and p70 S6, similar to that in Alzheimer's disease. Am J Pathol 2003;163:845-858.

139. Li L, Sengupta A, Haque N, Grundke-Iqbal I, Iqbal K. Memantine inhibits and reverses the Alzheimer type abnormal hyperphosphorylation of tau and associated neurodegeneration. FEBS Lett 2004;566:261-269.

140. Kampers T, Friedhoff P, Biernat J, Mandelkow EM, Mandelkow E. RNA stimulates aggregation of microtubule-associated protein tau into Alzheimer-like paired helical filaments. FEBS Lett 1996; 399:344-349.

141. Goedert M, Jakes R, Spillantini MG, Hasegawa M, Smith MJ, Crowther RA. Assembly of microtubule-associated protein tau into Alzheimer-like filaments induced by sulphated glycosaminoglycans. Nature 1996;383:550-553.

142. Arrasate M, Pérez M, Valpuesta JM, Avila J. Role of glycosaminoglycans in determining the helicity of paired helical filaments. Am J Pathol 1997;151:1115-1122.

143. Wilson DM, Binder LI. Free fatty acids stimulate the polymerization of tau and amyloid $\beta$ peptides: in vitro evidence for a common effector of pathogenesis in Alzheimer's disease. Am J Pathol 1997;150:2181-2195.

144. von Bergen M, Friedhoff P, Biernat J, Heberle J, Mandelkow EM, Mandelkow E. Assembly of $\tau$ protein into Alzheimer paired helical filaments depends on a local sequence motif $\left({ }^{306}\right.$ VQIVYK $\left.^{311}\right)$ forming $\beta$ structure. Proc Natl Acad Sci U S A 2000;97:5129-5134.

145. von Bergen M, Barghorn S, Li L, et al. Mutations of tau protein 
in frontotemporal dementia promote aggregation of paired helical filaments by enhancing local $\beta$-structure. J Biol Chem 2001;276:48165-48174.

146. Mandelkow E, von Bergen M, Biernat J, Mandelkow EM. Structural principles of tau and the paired helical filaments of Alzheimer's disease. Brain Pathol 2007;17:83-90.

147. Wille H, Drewes G, Biernat J, Mandelkow EM, Mandelkow E. Alzheimer-like paired helical filaments and antiparallel dimers formed from microtubule-associated protein tau in vitro. J Cell Biol 1992;118:573-584.

148. Avila J, Santa-María I, Pérez M, Hernández F, Moreno F. Tau phosphorylation, aggregation, and cell toxicity. J Biomed Biotechnol 2006;2006:74539.

149. Mi K, Johnson GV. The role of tau phosphorylation in the pathogenesis of Alzheimer's disease. Curr Alzheimer Res 2006;3:449463.

150. Cotman CW, Poon WW, Rissman RA, Blurton-Jones M. The role of caspase cleavage of tau in Alzheimer disease neuropathology. J Neuropathol Exp Neurol 2005;64:104-112.

151. Wang YP, Biernat J, Pickhardt M, Mandelkow E, Mandelkow EM. Stepwise proteolysis liberates tau fragments that nucleate the Alzheimer-like aggregation of full-length tau in a neuronal cell model. Proc Natl Acad Sci U S A 2007;104:10252-10257.

152. Bandyopadhyay B, Li G, Yin H, Kuret J. Tau aggregation and toxicity in a cell culture model of tauopathy. J Biol Chem 2007; 282:16454-16464.

153. Wischik CM, Edwards PC, Lai RY, Roth M, Harrington CR. Selective inhibition of Alzheimer disease-like tau aggregation by phenothiazines. Proc Natl Acad Sci U S A 1996;93:1121311218.

154. Pickhardt M, Gazova Z, von Bergen M, et al. Anthraquinones inhibit tau aggregation and dissolve Alzheimer's paired helical filaments in vitro and in cells. J Biol Chem 2005;280:3628 -3635.

155. Pickhardt M, Larbig G, Khlistunova I, et al. Phenylthiazolylhydrazide and its derivatives are potent inhibitors of tau aggregation and toxicity in vitro and in cells. Biochemistry 2007;46: 10016-10023.

156. Bulic B, Pickhardt M, Khlistunova I, et al. Rhodanine-based tau aggregation inhibitors in cell models of tauopathy. Angew Chem Int Ed Engl 2007;46:9215-9219.

157. Pickhardt M, Biernat J, Khlistunova I, et al. N-phenylamine derivatives as aggregation inhibitors in cell models of tauopathy. Curr Alzheimer Res 2007;4:397-402.

158. Meyer B, Klein J, Mayer M, et al. Saturation transfer difference NMR spectroscopy for identifying ligand epitopes and binding specificities. Ernst Schering Res Found Workshop 2004;(44): 149-167.

159. Zeiger E, Shelby MD, Ivett J, McFee AF. Mutagenicity testing of 5-(4-nitrophenyl)-2,4-pentadien-1-al (spy dust) and its metabolites in vitro and in vivo. Environ Mutagen 1987;9:269-280.

160. Hotta N, Sakamoto N, Shigeta Y, Kikkawa R, Goto Y; Diabetic Neuropathy Study Group in Japan. Clinical investigation of epalrestat, an aldose reductase inhibitor, on diabetic neuropathy in Japan: multicenter study. J Diabetes Complications 1996;10:168172.

161. Necula M, Chirita CN, Kuret J. Cyanine dye N744 inhibits tau fibrillization by blocking filament extension: implications for the treatment of tauopathic neurodegenerative diseases. Biochemistry 2005;44:10227-10237.

162. Chirita C, Necula M, Kuret J. Ligand-dependent inhibition and reversal of tau filament formation. Biochemistry 2004;43:28792887.

163. Honson NS, Jensen JR, Darby MV, Kuret J. Potent inhibition of tau fibrillization with a multivalent ligand. Biochem Biophys Res Commun 2007;363:229-234.

164. May BC, Fafarman AT, Hong SB, et al. Potent inhibition of scrapie prion replication in cultured cells by bis-acridines. Proc Natl Acad Sci U S A 2003;100:3416-3421.

165. Necula M, Kayed R, Milton S, Glabe CG. Small molecule inhibitors of aggregation indicate that amyloid $\beta$ oligomerization and fibrillization pathways are independent and distinct. J Biol Chem 2007;282:10311-10324.

166. Ravikumar B, Duden R, Rubinsztein DC. Aggregate-prone pro- teins with polyglutamine and polyalanine expansions are degraded by autophagy. Hum Mol Genet 2002;11:1107-1117.

167. Klionsky DJ, Emr SD. Autophagy as a regulated pathway of cellular degradation. Science 2000;290:1717-1721.

168. Webb JL, Ravikumar B, Atkins J, Skepper JN, Rubinsztein DC. $\alpha$-Synuclein is degraded by both autophagy and the proteasome. J Biol Chem 2003;278:25009-25013.

169. Berger Z, Ravikumar B, Menzies FM, et al. Rapamycin alleviates toxicity of different aggregate-prone proteins. Hum Mol Genet 2006; 15:433-442.

170. Tan JM, Wong ES, Kirkpatrick DS, et al. Lysine 63-linked ubiquitination promotes the formation and autophagic clearance of protein inclusions associated with neurodegenerative diseases. Hum Mol Genet 2008;17:431-439.

171. Rubinsztein DC, Ravikumar B, Acevedo-Arozena A, Imarisio S, O'Kane CJ, Brown SD. Dyneins, autophagy, aggregation and neurodegeneration. Autophagy 2005;1:177-178.

172. Rubinsztein DC, DiFiglia M, Heintz N, et al. Autophagy and its possible roles in nervous system diseases, damage and repair. Autophagy 2005;1:11-22.

173. Dickey CA, Dunmore J, Lu B, et al. HSP induction mediates selective clearance of tau phosphorylated at proline-directed Ser/ Thr sites but not KXGS (MARK) sites. FASEB J 2006;20:753755 .

174. Kamal A, Boehm MF, Burrows FJ. Therapeutic and diagnostic implications of Hsp90 activation. Trends Mol Med 2004;10:283290.

175. Cripps D, Thomas SN, Jeng Y, Yang F, Davies P, Yang AJ. Alzheimer disease-specific conformation of hyperphosphorylated paired helical filament-Tau is polyubiquitinated through Lys-48, Lys-11, and Lys-6 ubiquitin conjugation. J Biol Chem 2006;281: 10825-10838.

176. Morishima-Kawashima M, Hasegawa M, Takio K, Suzuki M, Titani K, Ihara Y. Ubiquitin is conjugated with amino-terminally processed tau in paired helical filaments. Neuron 1993;10:11511160.

177. Shimura H, Schwartz D, Gygi SP, Kosik KS. CHIP-Hsc70 complex ubiquitinates phosphorylated tau and enhances cell survival. J Biol Chem 2004;279:4869-4876.

178. Dickey CA, Yue M, Lin WL, et al. Deletion of the ubiquitin ligase CHIP leads to the accumulation, but not the aggregation, of both endogenous phospho- and caspase-3-cleaved tau species. J Neurosci 2006;26:6985-6996.

179. Petrucelli L, Dickson D, Kehoe K, et al. CHIP and Hsp70 regulate tau ubiquitination, degradation and aggregation. Hum Mol Genet 2004;13:703-714.

180. Sahara N, Murayama M, Mizoroki T, et al. In vivo evidence of CHIP up-regulation attenuating tau aggregation. J Neurochem 2005;94:1254-1263.

181. Kumar P, Ambasta RK, Veereshwarayya V, et al. CHIP and HSPs interact with $\beta$-APP in a proteasome-dependent manner and influence A $\beta$ metabolism. Hum Mol Genet 2007;16:848-864.

182. Karsten SL, Sang TK, Gehman LT, et al. A genomic screen for modifiers of tauopathy identifies puromycin-sensitive aminopeptidase as an inhibitor of tau-induced neurodegeneration. Neuron 2006;51:549-560.

183. Constam DB, Tobler AR, Rensing-Ehl A, Kemler I, Hersh LB, Fontana A. Puromycin-sensitive aminopeptidase: sequence analysis, expression, and functional characterization. J Biol Chem 1995;270:26931-26939.

184. Hersh LB. Characterization of membrane-bound aminopeptidases from rat brain: identification of the enkephalin-degrading aminopeptidase. J Neurochem 1985;44:1427-1435.

185. Sengupta S, Horowitz PM, Karsten SL, et al. Degradation of tau protein by puromycin-sensitive aminopeptidase in vitro. Biochemistry 2006;45:15111-15119.

186. Park SY, Ferreira A. The generation of a $17 \mathrm{kDa}$ neurotoxic fragment: an alternative mechanism by which tau mediates $\beta$-amyloid-induced neurodegeneration. J Neurosci 2005;25: 5365-5375.

187. Gamblin TC, Chen F, Zambrano A, et al. Caspase cleavage of tau: linking amyloid and neurofibrillary tangles in Alzheimer's disease. Proc Natl Acad Sci U S A 2003;100:10032-10037. 
188. Rissman RA, Poon WW, Blurton-Jones M, et al. Caspase-cleavage of tau is an early event in Alzheimer disease tangle pathology. J Clin Invest 2004;114:121-130.

189. Fasulo L, Ugolini G, Cattaneo A. Apoptotic effect of caspase-3 cleaved tau in hippocampal neurons and its potentiation by tau FTDP-mutation N279K. J Alzheimers Dis 2005;7:3-13.

190. Chong YH, Shin YJ, Lee EO, Kayed R, Glabe CG, Tenner AJ. ERK1/2 activation mediates $A \beta$ oligomer-induced neurotoxicity via caspase- 3 activation and tau cleavage in rat organotypic hippocampal slice cultures. J Biol Chem 2006;281:20315-20325.

191. Nerenberg ST, Prasad R. Radioimmunoassays for Ig classes G, A, $\mathrm{M}, \mathrm{D}$, and $\mathrm{E}$ in spinal fluids: normal values of different age groups. J Lab Clin Med 1975;86:887-898.

192. Broadwell RD, Sofroniew MV. Serum proteins bypass the bloodbrain fluid barriers for extracellular entry to the central nervous system. Exp Neurol 1993;120:245-263.

193. Zlokovic BV, Segal MB, Davson H, Lipovac MN, Hyman S, McComb JG. Circulating neuroactive peptides and the bloodbrain and blood-cerebrospinal fluid barriers. Endocrinol Exp 1990;24:9-17.

194. Poduslo JF, Curran GL. Amyloid $\beta$ peptide as a vaccine for Alzheimer's disease involves receptor-mediated transport at the blood-brain barrier. Neuroreport 2001;12:3197-3200.

195. LaRue B, Hogg E, Sagare A, et al. Method for measurement of the blood-brain barrier permeability in the perfused mouse brain: application to amyloid- $\beta$ peptide in wild type and Alzheimer's Tg2576 mice. J Neurosci Methods 2004;138:233-242.

196. Asuni AA, Boutajangout A, Quartermain D, Sigurdsson EM. Immunotherapy targeting pathological tau conformers in a tangle mouse model reduces brain pathology with associated functional improvements. J Neurosci 2007;27:9115-9129.

197. Rosenmann H, Grigoriadis N, Karussis D, et al. Tauopathy-like abnormalities and neurologic deficits in mice immunized with neuronal tau protein. Arch Neurol 2006;63:1459-1467.

198. Andoh T, Kuraishi Y. Expression of Fce receptor I on primary sensory neurons in mice. Neuroreport 2004;15:2029-2031.

199. Fabian RH, Ritchie TC. Intraneuronal IgG in the central nervous system. J Neurol Sci 1986;73:257-267.

200. Fabian RH, Petroff G. Intraneuronal IgG in the central nervous system: uptake by retrograde axonal transport. Neurology 1987; 37:1780-1784.

201. Dietzschold B, Kao M, Zheng YM, et al. Delineation of putative mechanisms involved in antibody-mediated clearance of rabies virus from the central nervous system [Erratum in: Proc Natl Acad Sci U S A 1992;89:9365]. Proc Natl Acad Sci U S A 1992;89:7252-7256.

202. Aihara N, Tanno H, Hall JJ, Pitts LH, Noble LJ. Immunocytochemical localization of immunoglobulins in the rat brain: relationship to the blood-brain barrier. J Comp Neurol 1994;342: 481-496.

203. Mohamed HA, Mosier DR, Zou LL, et al. Immunoglobulin Fc $\gamma$ receptor promotes immunoglobulin uptake, immunoglobulin-mediated calcium increase, and neurotransmitter release in motor neurons. J Neurosci Res 2002;69:110-116.

204. Lobo ED, Hansen RJ, Balthasar JP. Antibody pharmacokinetics and pharmacodynamics. J Pharm Sci 2004;93:2645-2668.

205. Masliah E, Rockenstein E, Adame A, et al. Effects of $\alpha$-synuclein immunization in a mouse model of Parkinson's disease. Neuron 2005; $46: 857-868$.

206. Orgogozo JM, Gilman S, Dartigues JF, et al. Subacute meningoencephalitis in a subset of patients with $\mathrm{AD}$ after $\mathrm{A} \beta 42$ immunization. Neurology 2003;61:46-54.

207. Connell JW, Rodriguez-Martin T, Gibb GM, et al. Quantitative analysis of tau isoform transcripts in sporadic tauopathies. Brain Res Mol Brain Res 2005;137:104-109.

208. Ishizawa K, Ksiezak-Reding H, Davies P, et al. A double-labeling immunohistochemical study of tau exon 10 in Alzheimer's dis- ease, progressive supranuclear palsy and Pick's disease. Acta Neuropathol 2000;100:235-244.

209. Buée L, Delacourte A. Comparative biochemistry of tau in progressive supranuclear palsy, corticobasal degeneration, FTDP-17 and Pick's disease. Brain Pathol 1999;9:681-693.

210. Takanashi M, Mori H, Arima K, Mizuno Y, Hattori N. Expression patterns of tau mRNA isoforms correlate with susceptible lesions in progressive supranuclear palsy and corticobasal degeneration. Brain Res Mol Brain Res 2002;104:210-219.

211. Chambers CB, Lee JM, Troncoso JC, Reich S, Muma NA. Overexpression of four-repeat tau mRNA isoforms in progressive supranuclear palsy but not in Alzheimer's disease. Ann Neurol 1999;46:325-332.

212. Caffrey TM, Joachim C, Paracchini S, Esiri MM, Wade-Martins R. Haplotype-specific expression of exon 10 at the human MAPT locus. Hum Mol Genet 2006;15:3529-3537.

213. Boutajangout A, Boom A, Leroy K, Brion JP. Expression of tau mRNA and soluble tau isoforms in affected and non-affected brain areas in Alzheimer's disease. FEBS Lett 2004;576:183189.

214. Glatz DC, Rujescu D, Tang Y, et al. The alternative splicing of tau exon 10 and its regulatory proteins CLK2 and TRA2-BETA1 changes in sporadic Alzheimer's disease. J Neurochem 2006;96: 635-644.

215. Kalbfuss B, Mabon SA, Misteli T. Correction of alternative splicing of tau in frontotemporal dementia and parkinsonism linked to chromosome 17. J Biol Chem 2001;276:42986-42993.

216. Puttaraju M, Jamison SF, Mansfield SG, Garcia-Blanco MA, Mitchell LG. Spliceosome-mediated RNA trans-splicing as a tool for gene therapy [Erratum in: Nat Biotechnol 1999;17:602 and Nat Biotechnol 2001;19:277]. Nat Biotechnol 1999;17:246-252.

217. Rodriguez-Martin T, Garcia-Blanco MA, Mansfield SG, et al. Reprogramming of tau alternative splicing by spliceosome-mediated RNA trans-splicing: implications for tauopathies. Proc Natl Acad Sci U S A 2005;102:15659-15664.

218. Liu X, Jiang Q, Mansfield SG, et al. Partial correction of endogenous $\triangle$ F508 CFTR in human cystic fibrosis airway epithelia by spliceosome-mediated RNA trans-splicing. Nat Biotechnol 2002; 20:47-52.

219. Chao H, Mansfield SG, Bartel RC, et al. Phenotype correction of hemophilia A mice by spliceosome-mediated RNA trans-splicing. Nat Med 2003;9:1015-1019.

220. Ishihara T, Hong M, Zhang B, et al. Age-dependent emergence and progression of a tauopathy in transgenic mice overexpressing the shortest human tau isoform. Neuron 1999;24:751-762.

221. Parness J, Horwitz SB. Taxol binds to polymerized tubulin in vitro. J Cell Biol 1981;91:479-487.

222. Zhang B, Maiti A, Shively S, et al. Microtubule-binding drugs offset tau sequestration by stabilizing microtubules and reversing fast axonal transport deficits in a tauopathy model. Proc Natl Acad Sci U S A 2005;102:227-231.

223. Michaelis ML, Seyb KI, Ansar S. Cytoskeletal integrity as a drug target. Curr Alzheimer Res 2005;2:227-229.

224. Michaelis ML. Ongoing in vivo studies with cytoskeletal drugs in tau transgenic mice. Curr Alzheimer Res 2006;3:215-219.

225. Matsuoka Y, Jouroukhin Y, Gray AJ, et al. A neuronal microtubule interacting agent, NAP, reduces tau pathology and enhances cognitive function in a mouse model of Alzheimer's disease. J Pharmacol Exp Ther 2008;325:146-153.

226. Roberson ED, Scearce-Levie K, Palop JJ, et al. Reducing endogenous tau ameliorates amyloid $\beta$-induced deficits in an Alzheimer's disease mouse model. Science 2007;316:750-754.

227. Hutton M. Missense and splice site mutations in tau associated with FTDP-17: multiple pathogenic mechanisms. Neurology 2001;56:S21-S25. 